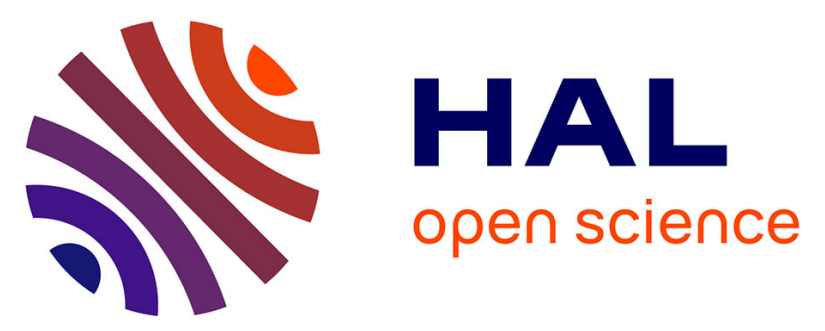

\title{
Experimental assessment of the sudden-reversal of the oxygen dilution effect on soot production in coflow ethylene flames II: soot radiation and flame transition analysis
}

Qianlong Wang, Jean-Louis Consalvi, Céline Morin, Guillaume Legros, Franklin Liu, Weiwei Cai, Haifeng Liu

\section{To cite this version:}

Qianlong Wang, Jean-Louis Consalvi, Céline Morin, Guillaume Legros, Franklin Liu, et al.. Experimental assessment of the sudden-reversal of the oxygen dilution effect on soot production in coflow ethylene flames II: soot radiation and flame transition analysis. Journal of Quantitative Spectroscopy and Radiative Transfer, 2020, 255, pp.1879-1352. 10.1016/j.jqsrt.2020.107261 . hal-03189320

\author{
HAL Id: hal-03189320 \\ https://hal.science/hal-03189320
}

Submitted on 2 May 2021

HAL is a multi-disciplinary open access archive for the deposit and dissemination of scientific research documents, whether they are published or not. The documents may come from teaching and research institutions in France or abroad, or from public or private research centers.
L'archive ouverte pluridisciplinaire HAL, est destinée au dépôt et à la diffusion de documents scientifiques de niveau recherche, publiés ou non, émanant des établissements d'enseignement et de recherche français ou étrangers, des laboratoires publics ou privés. 


\title{
Manuscript Details
}

\section{Manuscript number}

Title

Article type
JQSRT_2020_288_R1

Experimental assessment of the sudden-reversal of the oxygen dilution effect on soot production in coflow ethylene flames II : soot radiation and flame transition analysis

Full Length Article

\begin{abstract}
This paper presents the radiative characteristics of heavy smoking flames that formatted by oxygen being added to the fuel stream of a steady laminar ethylene diffusion flame. In this context, based on the experimental local soot temperature and volume fraction results, the soot local radiative fields are obtained by solving the Radiative Transfer Equation (RTE). Along with the diluted range (oxygen volume fraction $\mathrm{Xo2}$ from 0 to $32 \%$ ), the flame undergoes two significant transitions, i.e., smoking and non-smoking, however, only one remarkable radiative intensity transition between $30 \%$ and $32 \%$ is identified. The radiative loss due to the oxygen chemical effect is further assessed by comparing with that of $\mathrm{N} 2$ diluted flames. It is found that the chemical effect on radiative loss promotion is undermined by approximately $25 \%$, compared with that on soot formation promotion. In contrast, the oxygen dilution effect results in a similar reduction level on soot formation propensity and soot radiative loss. In addition, the correlations between relative soot consumption rate and cumulated radiative loss below the flame tip region are explored, and the results indicate that the initial relative oxidation rate at the position of $\mathrm{zFv}$, max (the peak location of flame cross-section mean soot volume fraction) and its residence time are two important factors that may affect the final flame smoking/nonsmoking transition. Eventually, these local soot radiative intensity fields, together with the local soot temperature and volume fraction fields provide a more comprehensive benchmark to refine the soot oxidation model as the ISF workshop required and understand the flame transition mechanism in the sooting flames.
\end{abstract}

\section{Keywords}

Corresponding Author

Corresponding Author's Institution

Order of Authors

Suggested reviewers
Soot; Local radiative intensity field; Ethylene diffusion flames; Smoking flames; Flame transition.

Qianlong WANG

Tianjin University

Qianlong WANG, Jean-Louis CONSALVI, Céline Morin, Guillaume Legros, Fengshan Liu, Weiwei Cai, Haifeng Liu

Shu Zheng, Muhammad Kashif, Zhiwei Sun 


\section{Submission Files Included in this PDF}

File Name [File Type]

rebuttal_jqsit.pdf [Response to Reviewers]

Highlights.docx [Highlights]

wangetal4_revise.pdf [Manuscript File]

soot_oxi.jpg [Figure]

$\mathrm{Rw} \_n 2 . j p g$ [Figure]

Rv.jpg [Figure]

radiation.jpg [Figure]

peak_soot_radiative.jpg [Figure]

max_vposition.jpg [Figure]

E_m_three.jpg [Figure]

three_field.jpg [Figure]

Radiative_three.jpg [Figure]

chem_effect.jpg [Figure]

rad_n2.jpg [Figure]

Declaration of Competing Interest.docx [Conflict of Interest]

statement .docx [Author Statement]

supplemental.docx [Supplementary Material]

\section{Submission Files Not Included in this PDF}

File Name [File Type]

wangetal4_revise.tex [LaTeX Source File]

Archive.zip [Supplementary Material]

To view all the submission files, including those not included in the PDF, click on the manuscript title on your EVISE Homepage, then click 'Download zip file'. 
Dear Prof. M. P. Menguc:

Our manuscript has been significantly revised following the two reviewers' comments. All the comments were answered point by point and the relevant modifications were outlined in blue in the revised manuscript. Also, the grammar relevant corrections were highlighted in red.

Therefore, we believe, these modifications enable the manuscript improvements. We appreciate that you could reconsider our manuscript to JQSRT.

Thank you very much for your time and reconsiderations.

Best regards,

Qianlong WANG

Associate Professor of Tianjin University

\section{Answers to Reviewer \#1}

This manuscript presents a study of soot radiative characteristics in a Santoro flame premixed with varying amounts of $\mathrm{O}_{2}$ and $\mathrm{N}_{2}$. Measurements of soot temperature and soot volume fraction are made using Modulated Absorption Emission and the soot radiative field was calculated using the radiative transfer equation. The authors differentiate the radiation losses due to chemical effects and dilution effects by comparing the corresponding $\mathrm{O}_{2}$ or $\mathrm{N}_{2}$ addition. It was found that the addition of $\mathrm{O}_{2}$ promoted soot radiative losses in the flame. Furthermore, the initial oxidation rate at the location of maximum soot volume would affect soot evolution in the flame tip. While the experimental measurements and results are of value to the sooting community, the reviewer recommends major revisions before publishing this work.

We appreciate the reviewer considered our work valuable for the community and recommended for publication after the modification.

1. The grammar of the manuscript should be significantly improved before publication. It was very challenging to read the manuscript as there were significant errors 
in sentence structure, word choice, etc. This made the message of the manuscript difficult to understand and focus on.

The manuscript has been thoroughly read and corrected for the grammar, sentence structure, typos, etc. The corresponding corrections are highlighted in RED in the revised manuscript.

2. Some discussion on uncertainty in the soot emission coefficient equation as well as the experimental measurements should be given. How would changing $E(m)$ affect the results? Several groups have shown $E(m)$ changing with HAB.

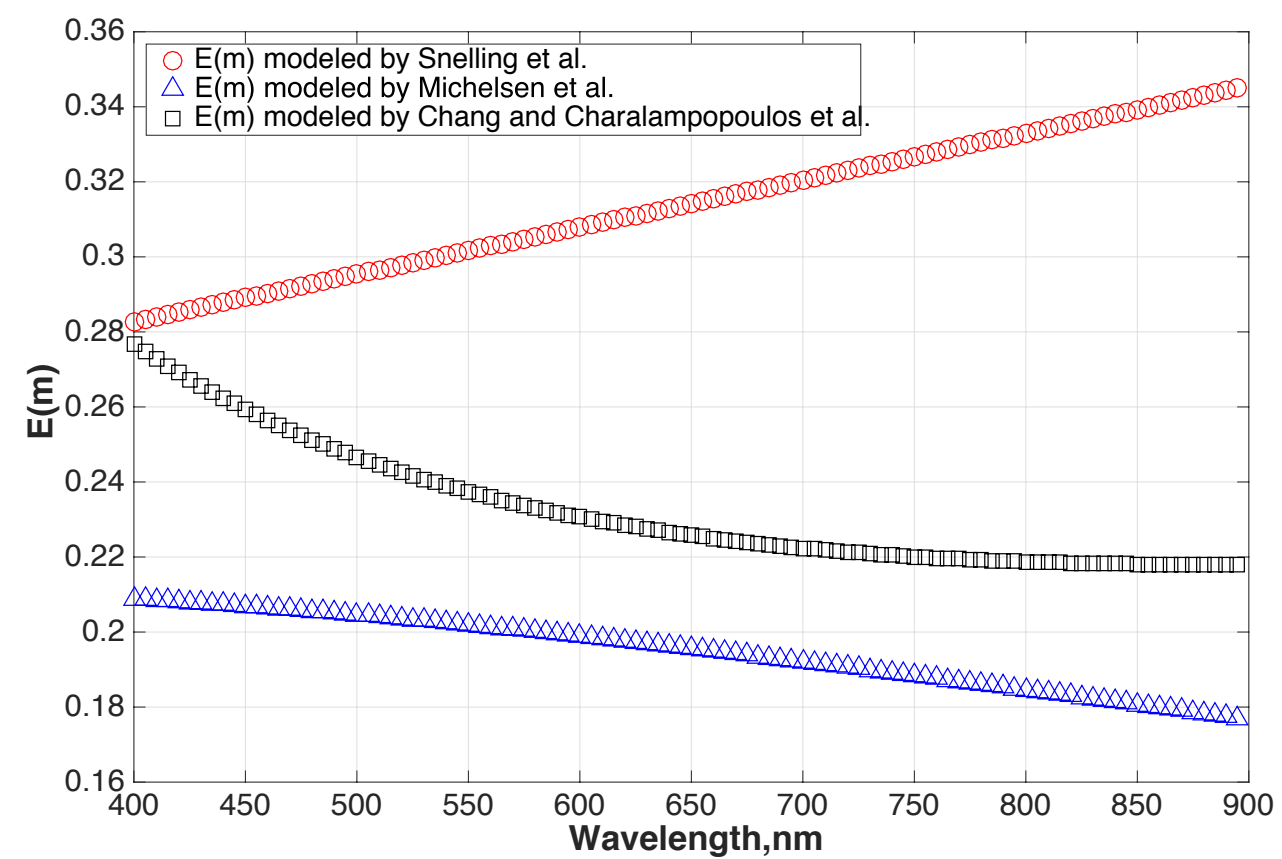

Fig.1, Evolution of the $E(m)$ with the wavelength in three models

We agree with the reviewer. In our paper, only the $E(m)$ model of the Chang and Charlampopulos [19] was used to calculate the soot emission coefficient, thereby the $\boldsymbol{q}^{\boldsymbol{R}}$. In the modification version, another two $E(m)$ models (Given by Snelling et al. [22] and Michelsen et al. [23]) were further used to calculate soot emission coefficient and the $\boldsymbol{q}^{\mathrm{R}}$.

Fig.1 shows the comparison of $E(m)$ variation with the wavelength in the three models. The $E(m)$ model given by Chang \& Charalampopoulos et al. is larger than that of Michelsen et al., while it is smaller than that of Snelling et al. Fig.2 displays the calculated 
$q^{R}$ by these three $E(m)$ models within the oxygen fraction from 0 to $32 \%$. As anticipated, the calculated soot radiative fields' absolute magnitudes vary with the magnitudes of $E(m)$. Yet, the transition trend within the oxygen fraction is unchanged. Fig.3 shows the normalized soot peak radiative intensity evolution with the oxygen fraction for the three models. It indicates that the model of $E(m)$ has a trivial influence on the relative amplitudes of soot radiative intensities within the oxygen fraction variations; thus, the $E(m)$ uncertainties do not affect the conclusions in our paper. These discussions were added to the revised paper as APPENDIX A.

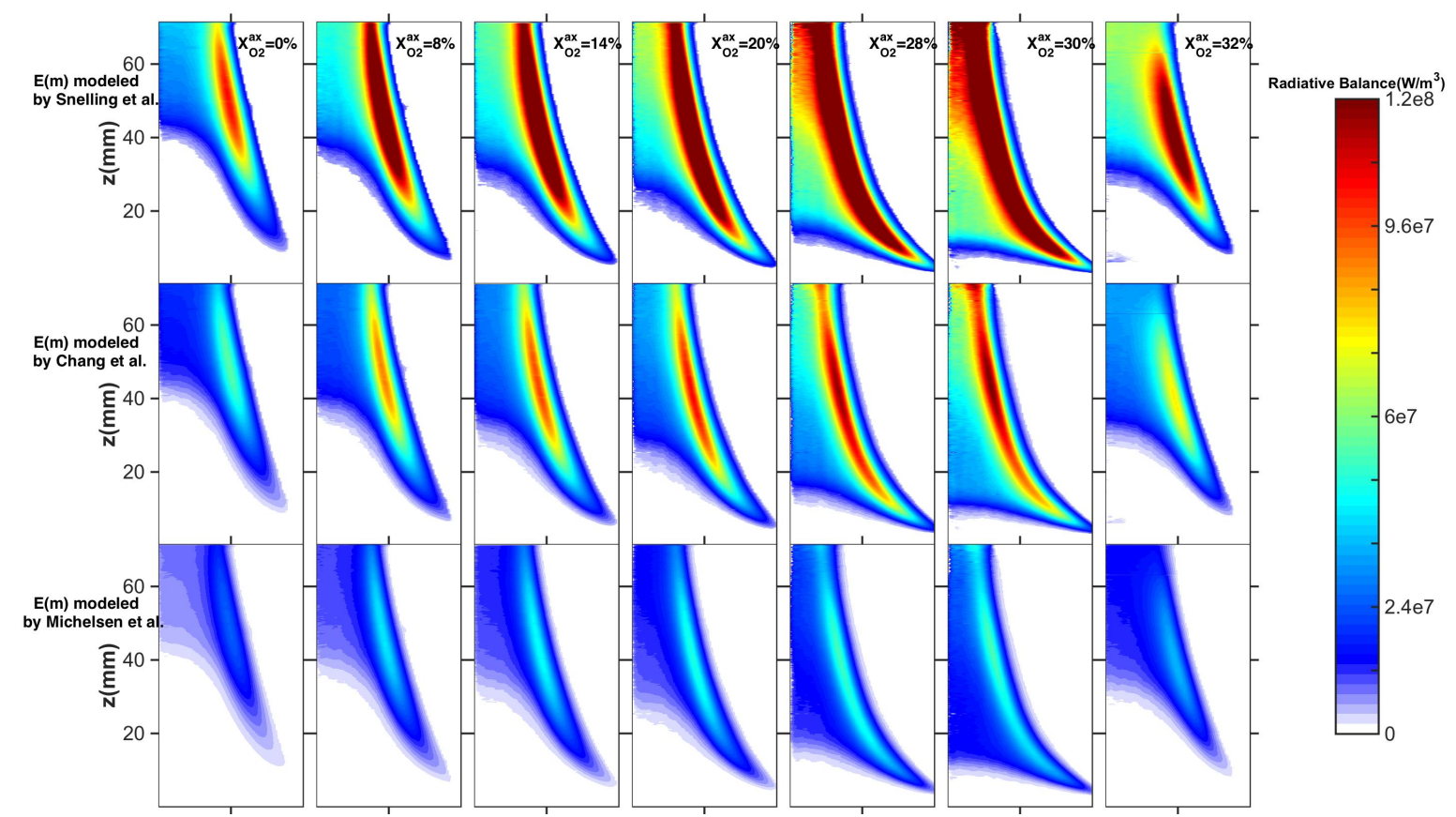

Fig.2, The calculated soot radiative fields variations with the oxygen fraction by three $E(m)$ models. Top row: $E(m)$ modeled by Snelling et al.; middle row: $E(m)$ modeled by Chang \& Charalampopoulos et al.; bottom row: $\mathrm{E}(\mathrm{m})$ modeled by Michelsen et al. 


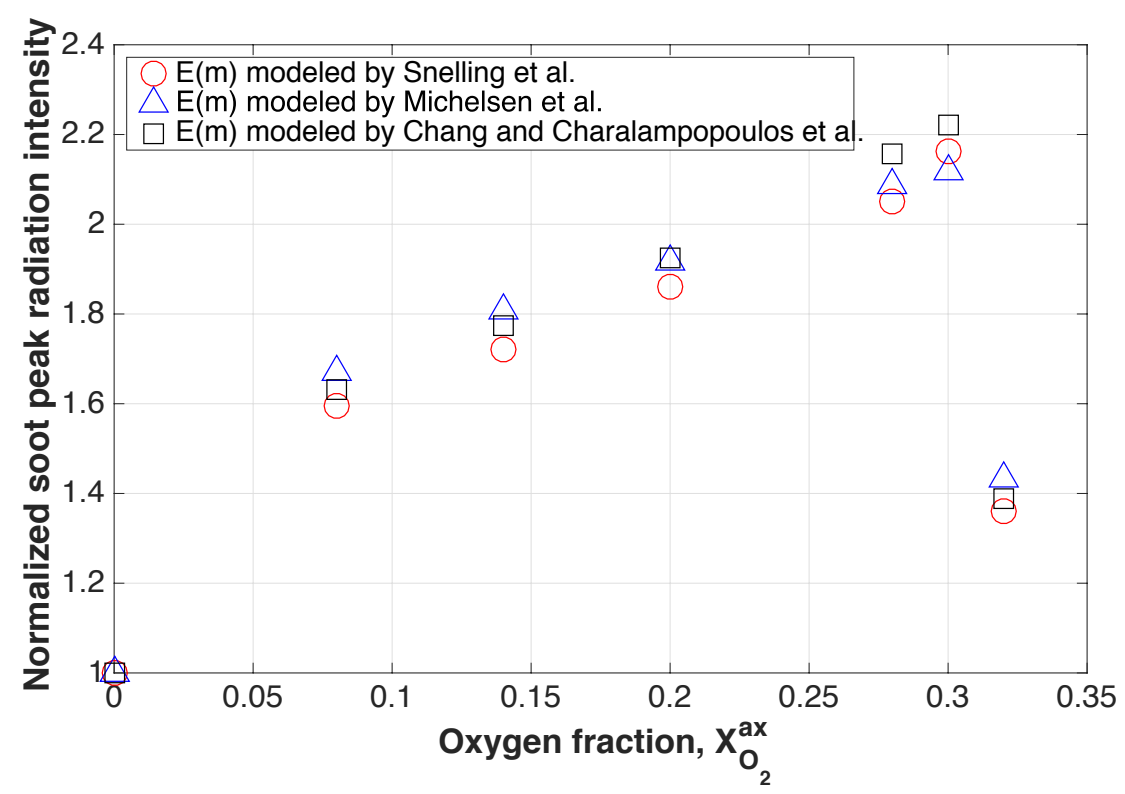

Fig.3, The normalized soot peak radiation intensity evolution with the oxygen fraction for the three models. All the data (open scatters) are normalized by their value at $\mathrm{X}_{02}{ }^{\mathrm{ax}}=0$.

3. Please give a summary as to why there is a transition in SVF between $\mathrm{X}_{\mathrm{O} 2}=30 \%$ to $\mathrm{X}_{\mathrm{O} 2}=32 \%$.

When the oxygen is incrementally added to the central fuel stream, the inner flame becomes more like a premixed flame, while the outer flame is a diffusion flame. It speculates that such a remarkable transition in the sooting tendency and the flame's shape are attributed to an intrinsic transformation in the overall structure of reaction zone, namely the intimate coupling between the inner premixed reaction zone and the outer diffusion flame. In short, the SVF transition is due to the overall structure of reaction zone transformation. This reason was provided in the first paragraph of subsection 4.1. of the revised manuscript.

\section{Secondary:}

1. All of the scatter plots use points that are small and difficult to distinguish at times. The font size in each of the figures is very small and difficult to read as well.

The font sizes of all the figures were enlarged, so did the relevant scatter points in the figures. 
2. A legend in Figure 3 would be useful.

The legends were added in the new Figure 3.

3. Why does Figure 3 not have vertical peak position for the $20 \%$ flame case?

Because the vertical position of the soot temperature peak is abnormal due to the data de-convolution processing and for better illustration of the vertical position evolution, the data for the oxygen fraction of $20 \%$ did not display in the plot.

4. Temperatures in Figure 1 would be easier to differentiate if the colorbar scale was chosen with more care.

The temperature scale in Fig. 1 was refined in the modification version.

5. The addition of stoichiometric mixture ratios in Table 1 would be useful for the premixed cases.

The equivalent ratios $(\phi)$ of oxygen-diluted cases were added to last column in Tab.1, which was calculated by the fuel and oxygen volume fractions in the central fuel stream.

\section{Answers to Reviewer \#2}

This paper presents an extension of the soot-radiation analysis earlier published in Refs. 15 \& 16. The previous work (Refs. 15 \& 16) reported data collected using an experimental-modeling technique originally described in Ref. 17. In this reviewer's understanding, the current manuscript does not describe newly collected data or significantly advances on the analyses published earlier. This, in this reviewer's opinion, is the major drawback of the work. In this reviewer's opinion, this paper does not provide a better understanding of the soot-radiation phenomena in laminar candle-like flames and can only be considered incremental. Please see below for specific questions.

We agree with the reviewer that this article is an extended discussion of our previous works $[15,16]$. That is the reason why the title is the same as the one of Ref.15. 
However, the highlight of the present paper is to unveil connections between the soot radiative loss and the flame smoking transition, completely different from that in the Ref.15 \&16. Furthermore, such systematical transition heavy sooting flames' datasets, especially the calculated soot local radiative fields are new results. These results provided as the supplemental materials are valuable for the numerical model validations, as pointed out by reviewer \#1.

1. Introduction: it is unnecessary to refer a non-peer reviewed publication (ISF workshop) as justification for the current study. Instead please provide the physical reasoning driving the study, i.e., why is the phenomenon being investigated relevant, etc.

We agree with the reviewer. The first paragraph of the introduction was revised to highlight the soot oxidation process that coupling in the flame radiation and soot emission processes, thus the relevant two latest references were added.

2. Experimental: table 1 is not easy to follow. Suggest providing separate sections for $\mathrm{N} 2$ and $\mathrm{O} 2$.

For the paper structure considerations, all the experimental parameters were better illustrated in Tab.1 in section 2. Therefore, the Tab.1 did not separate. However, the corresponding descriptions of the two sets of $\mathrm{N}_{2}$ and $\mathrm{O}_{2}$ experiments were rephrased and detailed in section 2 for legibility.

3. Experimental: it's clear that this paper simply uses data collected earlier and published in a previous set of publications; however, it is easier for the audience to follow the analyses if the experimental sketch with measurement locations, etc. are included and described in the current manuscript. This way, the reader doesn't have to repeatedly refer back to the previous publications. The analysis presented is not easy to follow on its own in any case and the reviewer had to revisit the previous publications several times to understand the details.

We agree with the reviewer. The basic experimental schematics and the measurement domain were further reminded as the second and third paragraph in section 2 . 
4. Results, section 4.1 "It is noted the soot radiative intensity (W) was calculated by qR multiplied by every discrete volume $V$, ie $5.9^{\star} 10^{\wedge}-13 \mathrm{~m}^{\wedge} 3^{\prime \prime}-$ where was this volume obtained from? The authors again force the reader to refer back to their previous work instead of providing enough details for easy consumption.

We agree with the reviewer. Since the horizontal $X$ scale and vertical $Z$ scale of every pixel in the calculated fields $\mathbf{q}^{\mathbf{R}}$ are approximately $7.4 \mathrm{e}-5 \mathrm{~m}$ and $1.07 \mathrm{e}-4$ $\mathrm{m}$, respectively. Thus, the discrete volume is about $\mathrm{V}=7.4 \mathrm{e}-5 \times 7.4 \mathrm{e}-5 \times 1.07 \mathrm{e}-4=$ $5.9 \mathrm{e}-13 \mathrm{~m}^{3}$. The details were specified in the first paragraph of subsection 4.1.

5. Results, section 4.1 - what is the physical reasoning for the "remarkable transition" that occurs between Chi_O2 of 30 and 32\%? Could the authors describe the physics behind this transition? Some elaboration would help the audience instead of them having to refer back to the previous publications.

When the oxygen is incrementally added to the central fuel stream, the inner flame becomes more like a premixed flame, while the outer flame is a diffusion flame. It speculates that such a remarkable transition in the sooting tendency and the shape of the flame are attributed to an intrinsic transformation in the overall structure of reaction zone, namely the intimate coupling between the inner premixed reaction zone and the outer diffusion flame.

We agree with the reviewer. The above transition reason was briefly provided in the first paragraph of subsection 4.1.

6. Results, Fig. 1 - several plots are from Ref. 15. Instead of re-publishing, please refer back to the results. The temperature colorbar range needs to be shortened; all the temperature contour plots look alike with the range currently selected. It's not easy to decipher the differences.

Since only four images were published in Ref.16 (Ref.15 in the original manuscript), there are three new SVF \& Temperature images and seven corresponding soot local radiative fields were provided in Fig.1 for comparison; therefore, we do not consider it as re-publishing. 
We agree with the reviewer. The temperature scale was refined to the range of 1250 2250K in the new version.

7. Results, Fig. 2 - in the label "red" range is used. Please include the wavenumber range in the caption. Also provide the reference value for the normalized soot radiative intensity for Chi_O2 $=0$.

The two wavelength ranges were added to the caption of Fig. 2 .

The total soot radiative intensity $(0.2347 \mathrm{~W})$ and the soot peak radiative intensity $(5.477 \mathrm{e})$ at $\mathrm{X}_{02}=0$ were provided in the first paragraph of subsection 4.1.

8. Results, Fig. 5 - the curves are from Ref. 15. Instead of re-publishing, please refer back to the results.

Indeed, the curves in Fig.5 were completely not the ones in Ref. 16 (Ref.15 in the original manuscript), though they looked similar.

In Ref.16, the cross-section integrated soot volume peaks were plotted to the corresponding oxygen/nitrogen fraction, whereas the peaks of soot radiative loss $\mathrm{R}_{v}$ (every profile in Fig.4) were plotted to the corresponding oxygen/nitrogen fraction in the Fig.5 in the present paper.

9. Results, Fig. 6 - the associated discussion in section 4.3 is difficult to follow. Trends for each curve is simply discussed but it's not possible to understand the physics behind the differences in each of the results.

The physics meaning of the curves in the Fig. 6 is the correlation between the relative soot oxidization rate (due to the soot oxidation assumed to dominate the soot formation beyond the location of $\mathrm{Z}_{\mathrm{Fv}, \max }$ ) and the cumulated soot radiative loss from $\mathrm{Z}_{\mathrm{Fv} \text {, max }}$ to $\mathrm{z}$. It tries to discuss the relation between the relative soot oxidization rate and the soot radiation loss. It has been clearly illustrated in the first paragraph of section 4.3.

10. Results, section 4.3 - sentences like "In general, the first part has the negative slope, while the second part has the positive slope" do not help the audience one bit. From Fig. 6, it's quite clear that such a mathematical trend occurs for all the curves. 
We agree with the reviewer. This sentence is rephrased and the physics meaning of the peak is further detailed.

The physics meaning of the peaks of the curves in Fig.6 was the transition of relative soot oxidation rate. It indicated that the relative soot consumption rate turned to weak and eventually the rate decayed to zero, along with the higher cumulated radiation loss.

This modification was added to the first paragraph of section 4.3 and helped the readers to understand.

11. Results, section 4.3 - "...larger relative soot oxidation rate maintains a longer time until it reaches the peak....": time is not on either axes in Fig. 6 . How is time or residence time for soot inferred then?

We agree with the reviewer. The residence time that accounted from the location of $\mathrm{Z}_{\mathrm{F}_{\mathrm{v}, \max }}$ to the location of $\mathrm{Z}_{\mathrm{dF}_{\mathrm{v}} / \text { dzlpeak }}$ could be estimated by:

$$
\tau=\frac{z_{F v \cdot \max }-z_{d F v / d z l p e a k}}{v^{a x}}
$$

These correlated modifications were revised to the first paragraph of section 4.3 and the residence times corresponding to the 7 oxygen-diluted conditions were listed in the last column of Tab.2.

12. 1) Conclusion - again, the "remarkable transition" between Chi_O2 of 30 and $32 \%$ is mentioned but in this reviewer's opinion, this is not a conclusion but simply an observation. "...the peaks of soot radiative intensity fields remain at the flame annular position." - this is a known fact established by experimental studies; the current study does not provide any new information.

2) The "oxygen chemical effect" repeatedly mentioned is not clearly identified in the current analysis. The term is used without providing some physical/chemical details of the "chemical effect" that the authors are describing. Is this simply soot oxidizing due to $\mathrm{O} / \mathrm{O} 2 / \mathrm{OH}$ ?

3) "Residence time" - is not explicitly resolved in this study or the previous associated studies but is instead inferred from analysis involving other quantities. 
This should be clarified to the audience or additional description should be included to associate the analysis with the residence time.

12.1. The soot radiative fields computed by the RTE are the new ones that have not been carefully checked before. We think it is necessary to point out the soot radiative field characteristics difference, compared to the previous soot temperature and volume fraction results. Though it may be observed by the experiments, the conclusion, i.e., peak radiative position variations, could not be drawn by just "simple" experimental observation.

12.2. We agree with the reviewer. Indeed, the oxygen chemical effect not only has the soot oxidation influence, also affects the soot formation pathway variations. The definition of oxygen chemical effect is further explained in the third paragraph of section 4.2 .

12.3. The "Residence time" issues have been addressed in the revised first paragraph of section 4.3. Please refer to the answer to question 11. 


\section{Highlights}

- Based on the experimental local soot temperature and volume fraction results, the soot local radiative fields are obtained by solving the Radiative Transfer Equation (RTE).

- It is found that the oxygen chemical effect on soot radiative loss promotion is undermined by approximately 25\%, compared with that on soot formation promotion. In contrast, the oxygen dilution effect results in a similar reduction level on soot formation propensity and soot radiative loss.

- The initial relative oxidation rate at the position of $\mathrm{z}_{\mathrm{Fv} \text {,max }}$ (the peak location of flame crosssection mean soot volume fraction) and its residence time are two important factors that may affect the final flame smoking/non-smoking transition. 


\title{
Experimental assessment of the sudden-reversal of the oxygen dilution effect on soot production in coflow ethylene flames II : soot radiation and flame transition analysis
}

\author{
Qianlong Wang ${ }^{\mathrm{a}, *}$, Jean-Louis Consalvi $^{\mathrm{b}}$, Celine Morin ${ }^{\mathrm{c}}$, Guillaume Legros ${ }^{\mathrm{d}}$, Fengshan Liu ${ }^{\mathrm{e}}$, \\ Weiwei Cai ${ }^{\mathrm{f}}$, Haifeng $\mathrm{Liu}^{\mathrm{a}}$ \\ ${ }^{a}$ State Key Laboratory of Engines, Tianjin University, 300072, Tianjin, China \\ ${ }^{b}$ Aix-Marseille Université, IUSTI/UMR CNRS 7343, 5 rue E. Fermi, Marseille, 13453, Cedex 13, France \\ ${ }^{c}$ Univ. Polytechnique, Hauts-de-France, CNRS, UMR 8201-LAMIH, 59313 Valenciennes, France \\ ${ }^{d}$ Sorbonne Universités, CNRS, UMR 7190 Institut Jean le Rond d'Alembert, F-75005 Paris, France \\ ${ }^{e}$ Measurement Science and Standards, National Research Council of Canada, Ottawa, Ontario, Canada. \\ ${ }^{f}$ Key Lab of Education Ministry for Power Machinery and Engineering, School of Mechanical Engineering, \\ Shanghai Jiao Tong University, 800 Dongchuan Road, Shanghai 200240, China
}

\section{Abstract}

This paper presents the radiative characteristics of heavy smoking flames that formatted by oxygen being added to the fuel stream of a steady laminar ethylene diffusion flame. In this context, based on the experimental local soot temperature and volume fraction results, the soot local radiative fields are obtained by solving the Radiative Transfer Equation (RTE). Along with the diluted range (oxygen volume fraction $\mathrm{X}_{\mathrm{O}_{2}}^{a x}$ from 0 to $32 \%$ ), the flame undergoes two significant transitions, i.e., smoking and non-smoking; however, only one remarkable radiative intensity transition between $30 \%$ and $32 \%$ is identified. The radiative loss due to the oxygen chemical effect is further assessed by comparing with that of $\mathrm{N}_{2}$ diluted flames. It is found that the chemical effect on radiative loss promotion is undermined by approximately $25 \%$, compared with that on soot formation promotion. In contrast, the oxygen dilution effect results in a similar reduction level on soot formation propensity and soot radiative loss. In addition, the correlations between relative soot consumption rate and cumulated radiative loss below the flame tip region are explored, and the results indicate that the initial relative oxidation rate at the position of $z_{F_{v, \max }}$ (the peak location of flame cross-section mean soot volume fraction) and its residence time are two important factors that may affect the final flame smoking/non-smoking transition. Eventually, these local soot radiative intensity fields, together with the local soot temperature and volume fraction fields, provide a more comprehensive

\footnotetext{
${ }^{*}$ Corresponding author.

Email address: wangqianlong@tju.edu.cn (Qianlong Wang)
} 
benchmark to refine the soot oxidation model as the ISF workshop required and understand the flame transition mechanism in the sooting flames.

Keywords: Soot, Local radiative intensity field, Ethylene diffusion flames, Smoking flames, Flame transition

\section{Introduction}

The soot oxidation process was identified as the priority process to further understand the combustion mechanisms that control soot emission from the academic flames to the practical combustion equipment. The soot oxidation kinetics depends on the soot particle age, size, residence time and morphology, etc., in which we have not yet fully understood currently [1,2]. Radiation from soot could be the predominant factor that coupling among soot formation, oxidation and flame smoking transition in flames. Yet, few studies focused on the transition process between non-smoking flames to smoking flames.

Extensive experimental and simulation studies undertook the non-smoking flames, which indicated the soot was completely consumed before the flame extinction on the flame tip $[3,4,5]$. In contrast, the smoking (sooting) flame means that the soot escapes through the flame tip. This concept is consistent with the smoke point, which is a qualitative measure of fuel soot propensity that originally judges the quality of the liquid fuels [6]. Glassman [7] defined the smoke point by the height of the "flame breakthrough, leading a wing-like appearance to the flame's luminous envelope". And the details were further extensively explored and documented [8, 9].

Few experimental studies focused on the after-transition smoking flame to further unveil the sooting flame characteristics to gain insights into soot oxidation process. Santoro et al. [10] systematically studied a set of four ethylene diffusion flames with fuel flowrate from $0.138 \mathrm{~L} / \mathrm{min}$ to $0.294 \mathrm{~L} / \mathrm{min}$ and a smoking transition was observed between the fuel flowrate of $0.276 \mathrm{~L} / \mathrm{min}$ and $0.294 \mathrm{~L} / \mathrm{min}$. The flame temperature and soot volume fraction results indicated that the smoking transition was controlled by the soot formation and oxidation rate near the flame annular region, not in the center of the flame. Megaridis and Dobbins [11] further examined two of these flames, i.e., non-smoking and smoking flame, in terms of soot morphological observations via sampling technique, and found the soot inception and surface growth rate were almost identical for both 
flames, while the lower soot oxidation rate was attributed to the smoking phenomenon. Recently, Bonnety et al. [12] studied the five Santoro-type flames with the increased ethylene flowrate from $0.191 \mathrm{~L} / \mathrm{min}$ to $0.248 \mathrm{~L} / \mathrm{min}$, also the lightly smoking flame was found in the last flame and attributed the smoking phenomenon to the local radiative loss quenching the soot oxidation in the vicinity of the smoking flame tip. On the other hand, Liu et al. [13] firstly predicted this smoking transition in the numerical approach, in which two temperature-dependent correction factors for the oxidation rates by $\mathrm{O}_{2}$ and $\mathrm{OH}$ were proposed to reconcile this smoking transition behavior. Lately, Khosous and Dwokin [15] incorporated the thermal age $\left(\mathrm{T}_{a}[14]\right)$ into the $\mathrm{O}_{2}$ reaction probability parameter $\alpha$ to implement the oxidation model and also successfully mimicked this flame smoking transition process. It based on the perception that $\mathrm{OH}$ radical and $\mathrm{O}_{2}$ took the main responsibility for soot oxidation in the soot formation region (lower in the flame) and the upper-flame region, respectively. It is noted that in all the above-mentioned studies, the transited sooting flames were achieved by increasing the fuel flowrate. It implied that the chemical effect could not be isolated due to different residence time in the sooting flame transition process. Above that, the maximum local soot volume fraction in these flames was approximately only $10 \mathrm{ppm}$. Indeed, the fuel or oxidizer chemical effect on soot propensity and high soot loading level in flames could not be circumvented in practical combustion scenarios.

In our previous work [16], the heavy smoking flame transition due to the oxygen diluted in the fuel ethylene stream of the Santoro flame was systematically documented and the oxygen chemical effect on sooting tendency was also isolated by comparison with the $\mathrm{N}_{2}$ diluted flames. Moreover, the stable transitional oxygen mole fraction of about $31 \%$ was also identified by the coflow chemical composition variation experiments. As noted by Khosous and Dwokin [15], the soot radiation should be considered in the simulation to predict the accurate temperature in heavily sooting flame. Hence, the accurate experimental soot volume fraction, temperature and radiative field are essential to further refine the soot oxidation model in the numerical studies.

In this article, these heavy sooting flames of oxygen diluted ethylene diffusion flames were revisited and the corresponding local radiative fields were computed based on the previously measured local soot temperature and volume fraction fields. Then, the soot radiative loss due to the oxygen chemical effect was further illustrated by comparison with that of $\mathrm{N}_{2}$ diluted flames. Eventually, the 
correlations between relative soot consumption rate and cumulated radiative loss of heavy sooting flames were detailed to trace the flame transition reason. These results gain insightful knowledge in the soot radiation and offer a more comprehensive benchmark to refine the soot oxidation model as the International Sooting Flame (ISF) workshop required, and to understand the heavy sooting flames transition mechanism.

\section{Experimental local soot temperature and volume fraction fields}

\begin{tabular}{|c|c|c|c|c|c|c|c|}
\hline \multicolumn{2}{|c|}{ Basic Santoro flame } & \multicolumn{2}{|c|}{$\mathrm{N}_{2}$ diluted $[17]$} & \multicolumn{4}{|c|}{$\mathrm{O}_{2}$ diluted $[16]$} \\
\hline $\begin{array}{c}\mathrm{V}_{\text {air }}^{c o} \\
(\mathrm{~L} / \mathrm{min})\end{array}$ & $\begin{array}{c}\mathrm{V}_{C_{2} H_{4}}^{a x} \\
(\mathrm{~L} / \mathrm{min})\end{array}$ & $\begin{array}{c}V_{N_{2}}^{a x} \\
(\mathrm{~L} / \mathrm{min})\end{array}$ & $\begin{array}{l}X_{N_{2}}^{a x} \\
(\%)\end{array}$ & $\begin{array}{c}V_{O_{2}}^{a x} \\
(\mathrm{~L} / \mathrm{min})\end{array}$ & $\begin{array}{l}X_{O_{2}}^{a x} \\
(\%)\end{array}$ & $\begin{array}{c}\mathrm{SVF}_{\text {peak }} \\
(\mathrm{ppm})\end{array}$ & $\phi$ \\
\hline \multirow{8}{*}{43} & \multirow{8}{*}{0.231} & 0 & 0 & 0 & 0 & 9.7 & $\infty$ \\
\hline & & 0.02 & 8 & 0.02 & 8 & 14.8 & 34.2 \\
\hline & & 0.06 & 20 & 0.04 & 14 & 17.8 & 17.1 \\
\hline & & 0.09 & 28 & 0.06 & 20 & 23.8 & 11.4 \\
\hline & & 0.11 & 32 & 0.09 & 28 & 42.5 & 7.6 \\
\hline & & 0.14 & 38 & 0.10 & 30 & 55.0 & 6.8 \\
\hline & & 0.2 & 46 & 0.11 & 32 & 11.7 & 6.2 \\
\hline & & 0.3 & 56 & & & & \\
\hline
\end{tabular}

The local soot temperature and volume fraction (SVF) fields of the oxygen or nitrogen dilution Santoro-type flames have been detailed in previous studies [16, 17]. Major experimental procedures and parameters are reminded here. The diluted flames were investigated on a basic Santoro flame (a steady axis-symmetric ethylene laminar diffusion flame), in which the central flow rates of ethylene (within the inner diameter $\mathrm{d}_{F}=11 \mathrm{~mm}$ ) and coflowing air streams (within a concentric brass cylinder of $102 \mathrm{~mm}$ inner diameter), i.e., $\mathrm{V}_{C_{2} H_{4}}^{a x}$ and $\mathrm{V}_{a i r}^{c o}$, were fixed at the constant values of 0.231 $\mathrm{L} / \mathrm{min}$ and $43 \mathrm{~L} / \mathrm{min}$, respectively. As reminded in Tab.1, in the first set experiments, the nitrogen was gradually added to the central fuel stream with the flow rate ranging from 0 to $0.3 \mathrm{~L} / \mathrm{min}[17]$, while in the second set of experiments, the oxygen was added to the fuel stream within the ranging from 0 to $0.11 \mathrm{~L} / \mathrm{min}[16]$. The oxygen diluted seven flames were highlighted in the present study since the Santoro flame immediately transmitted to the heavily smoking flame when the oxygen was added to the fuel stream and the flame transmitted back to a non-smoking flame when the oxygen fraction $\mathrm{X}_{\mathrm{O}_{2}}^{a x}$ reached $32 \%$. The maximum of local soot volume fraction $\left(\mathrm{SVF}_{\text {peak }}\right)$ and the corresponding equivalent ratio in every flame was listed in the last two columns of Tab.1.

The Modulated Absorption Emission (MAE) technique was used for local soot temperature 
and volume fraction field retrieval [18]. The major features of MAE were briefly reminded. Two continuous-wave lasers operating at two wavelengths, i.e., $645 \mathrm{~nm}$ and $785 \mathrm{~nm}$, were expanded to provide $70 \mathrm{~mm}$ diameter collimated beams. When the laser was on, the laser beam attenuation measurement through the flame is conducted using two identical CMOS cameras at each wavelength. In the opposite, the flame spontaneous radiation images were also imaged by the corresponding camera as the laser was off.

Then the local absorption coefficient $\kappa_{\lambda}$ and the local emission rate $\kappa_{\lambda} I_{b, \lambda}$ at both wavelengths were retrieved by the onion-peeling method with Tikhonov regularization [18]. The soot volume fraction field was calculated from the red absorption coefficient by modeling of the soot refractive index[19]. In contrast, the soot temperature field was retrieved by the ratio of the local spectral emission rates from the two wavelengths, which was free of soot refractive index wavelength-dependent issue. Due to the collimated laser beam's diameter limitation, the flame beyond the height of 70 mm cannot be probed.

\section{Local soot radiative computations}

Assuming the soot is a non-scattering medium and the majority source of the visible radiation in the ethylene diffusion flame, the local soot radiative field in the flames could be solved by the RTE via Finite Volume Method, which has been detailed in Refs. [20, 21]. The major equation reminded as:

$$
\nabla \mathbf{q}^{R}=\int_{0}^{\infty}\left(4 \pi \kappa_{\lambda} B_{\lambda}-\kappa_{\lambda} \int_{4 \pi} I_{\lambda} d \Omega\right) d \lambda
$$

Provided the local soot temperature and volume fraction fields (from the Refs.[16, 17]), the soot radiative field could be calculated through the above equation. $\kappa_{\lambda}$ is soot emission coefficient, which could be modeled by $6 \pi E(m) S V F / \lambda$, and soot refractive index function $\mathrm{E}(\mathrm{m})$ was provided by Chang and Charlampopulos [19]. While $I_{\lambda}$ is the soot radiative intensity at wavelength $\lambda, B_{\lambda}$ is the blackbody radiation, and $\Omega$ is the solid angle. The further discussions of different $\mathrm{E}(\mathrm{m})$ models $[22,23]$ influence on the soot radiative field calculation are detailed in the APPENDIX A. 


\section{Results and discussion}

\subsection{Local soot radiative fields}
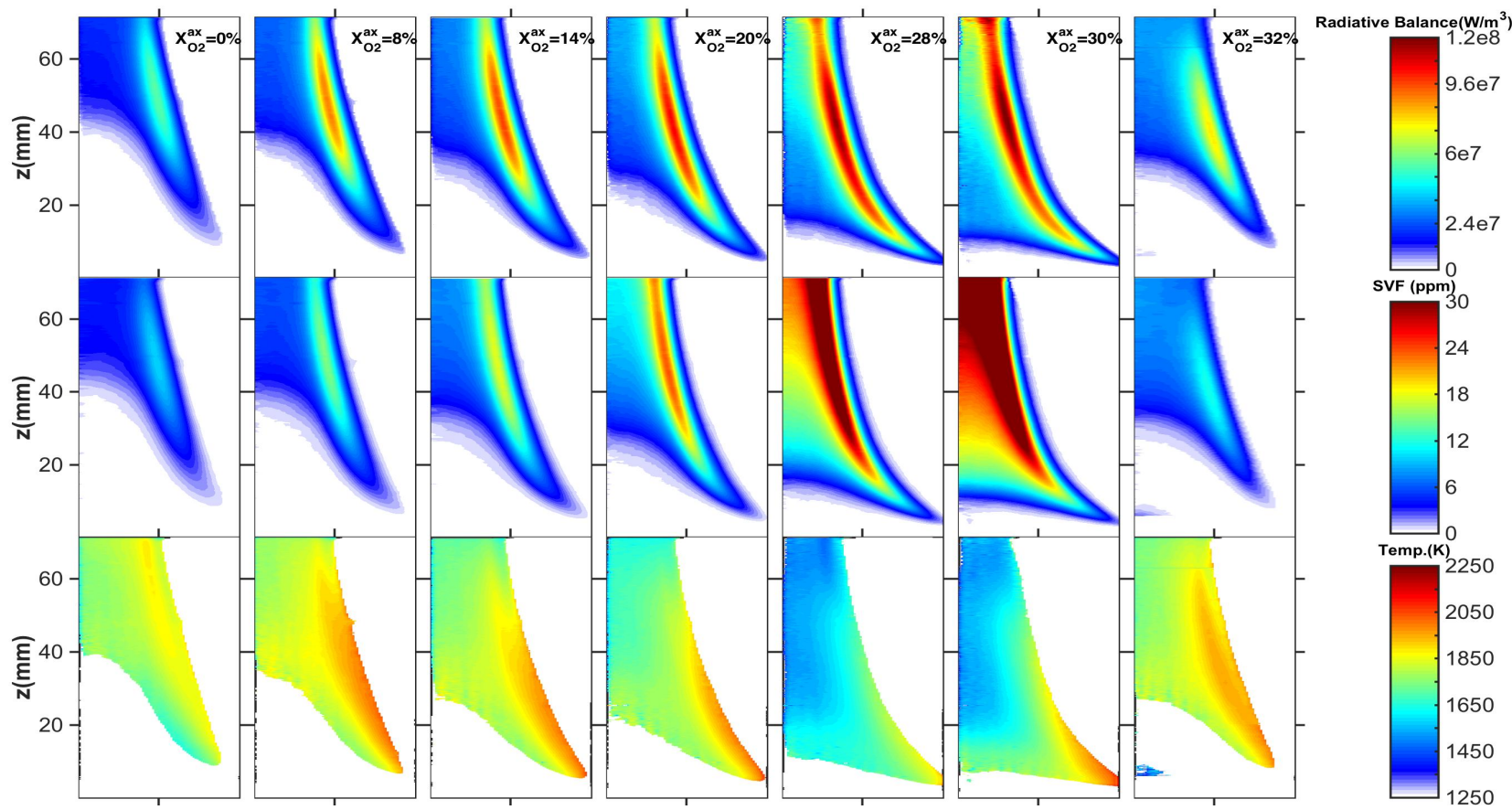

Figure 1: Local soot radiative fields computed from the experimental local soot volume fraction and temperature fields for oxygen fraction $\left(X_{\mathrm{O}_{2}}^{a x}\right)$ ranging from 0 to $32 \%$ in the central stream. Top row: soot radiative fields; middle row: SVF fields; bottom row: soot temperature fields.

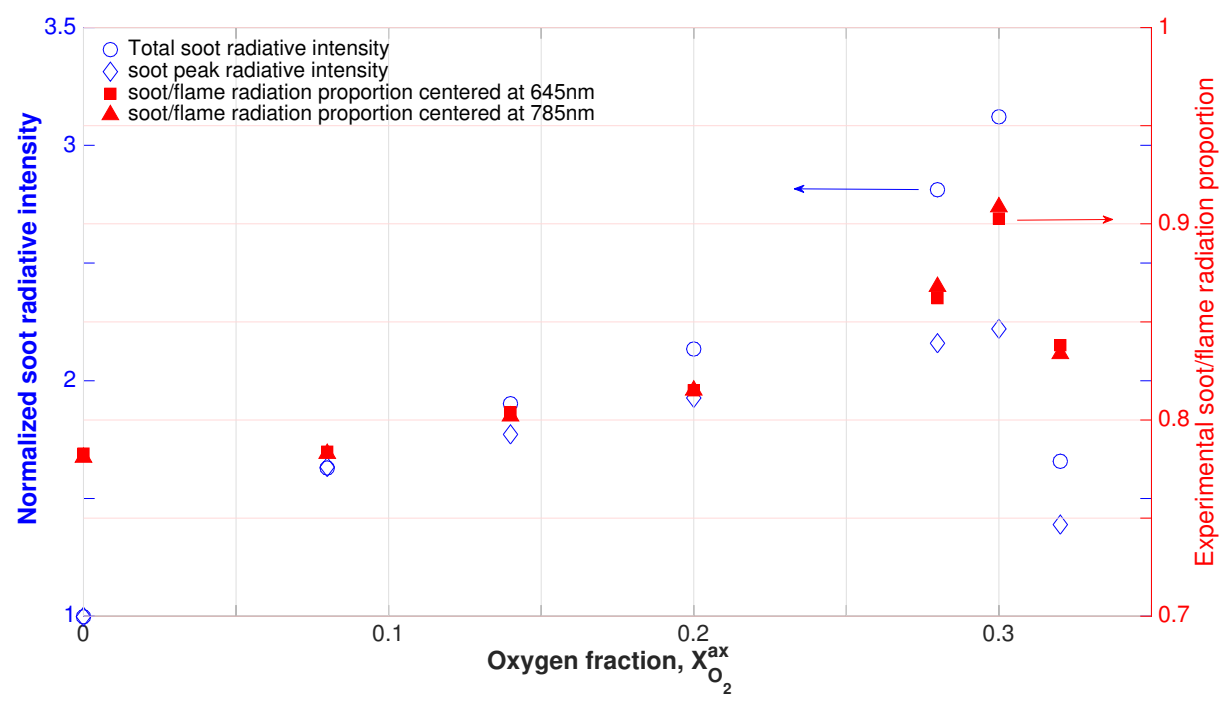

Figure 2: Left y-axis: normalized soot radiative intensity for oxygen fraction $X_{\mathrm{O}_{2}}^{a x}$ ranging from 0 to $32 \%$. All the data (blue open scatters) are normalized by their value at $X_{O_{2}}^{a x}=0$. Right y-axis: proportions evolutions of the soot two spectral radiative intensity to the total flame radiative intensity for oxygen fraction $X_{\mathrm{O}_{2}}^{a x}$ ranging from 0 to $32 \%$. The red square scatters represent the wavelength range of 635 to $655 \mathrm{~nm}$, while the red triangle scatters for the wavelength range of 780 to $790 \mathrm{~nm}$. 
Figure 1 demonstrates the computed local soot radiative fields with oxygen diluted fraction from 0 to $32 \%$ (top row), and the corresponding local soot temperature and SVF fields are also represented in the last two rows. Since the entire flame is axial symmetry, only the right half of the flame results are shown. It is noted that the horizontal X scale and vertical Z scale of every pixel in the calculated fields $\mathbf{q}^{R}$ are approximately $7.4^{*} 10^{-5} \mathrm{~m}$ and $1.07^{*} 10^{-4} \mathrm{~m}$, respectively. Thus the soot radiative intensity $(\mathrm{W})$ was calculated by $\mathbf{q}^{R}$ multiplied by every discrete volume $V$, i.e., $5.9^{*} 10^{-13} \mathrm{~m}^{3}$. As anticipated, though the flame experiences two significant smoking/non-smoking transitions, i.e., $\mathrm{X}_{\mathrm{O}_{2}}^{a x}$ at $8 \%$ and $32 \%$, during this procedure, the soot radiative intensity goes through only one remarkable transition between $\mathrm{X}_{\mathrm{O}_{2}}^{a x} 30 \%$ and $32 \%$, as the soot temperature and volume fraction fields do. When the oxygen is incrementally added to the central fuel stream, the inner flame becomes more like a premixed flame, while the outer flame is a diffusion flame. It speculates that such a remarkable transition in the sooting tendency and the flame's shape are attributed to a fundamental transformation in the overall structure of reaction zone, namely the intimate coupling between the inner premixed reaction zone and the outer diffusion flame [16]. In short, the SVF transition is due to the overall structure of reaction zone transformation. It is further verified by the total soot radiative intensity and the soot peak radiative intensity variations with the oxygen fraction. As displayed by the blue open scatters in Fig.2, the transition also happens between $\mathrm{X}_{\mathrm{O}_{2}}^{a x}$ $30 \%$ and $32 \%$. Noted that all the data are normalized by their values at $X_{O_{2}}^{a x}=0$, namely the total initial soot radiative intensity and the soot peak radiative intensity are $0.2347 \mathrm{~W}$ and $5.477^{*} 10^{7}$ $\mathrm{W} / \mathrm{m}^{3}$, respectively.

As an important parameter in flame propagation and extinction issue, the soot radiation proportion within the total flame radiation is further quantified from the experimental flame spectral radiation measurements in MAE. The flame spectral radiation at soot confident region, i.e., SVF $\geq 0.5 \mathrm{ppm}$, is cumulated to calculate the corresponding soot spectral radiative intensity. The red solid scatters in Fig.2 show the evolution of the soot two spectral radiation proportion centered at $645 \mathrm{~nm}$ and $785 \mathrm{~nm}$. The soot spectral radiation proportion approximately increases from 0.78 to 0.91 when the $X_{\mathrm{O}_{2}}^{a x}$ rises from 0 to $30 \%$ followed by a reduction at $32 \%$.

Moreover, the evolutions of the vertical peak positions of soot temperature, volume fraction and radiative intensity fields are demonstrated in Fig.3. At $X_{O_{2}}^{a x}=0$, these three peaks locate at the 


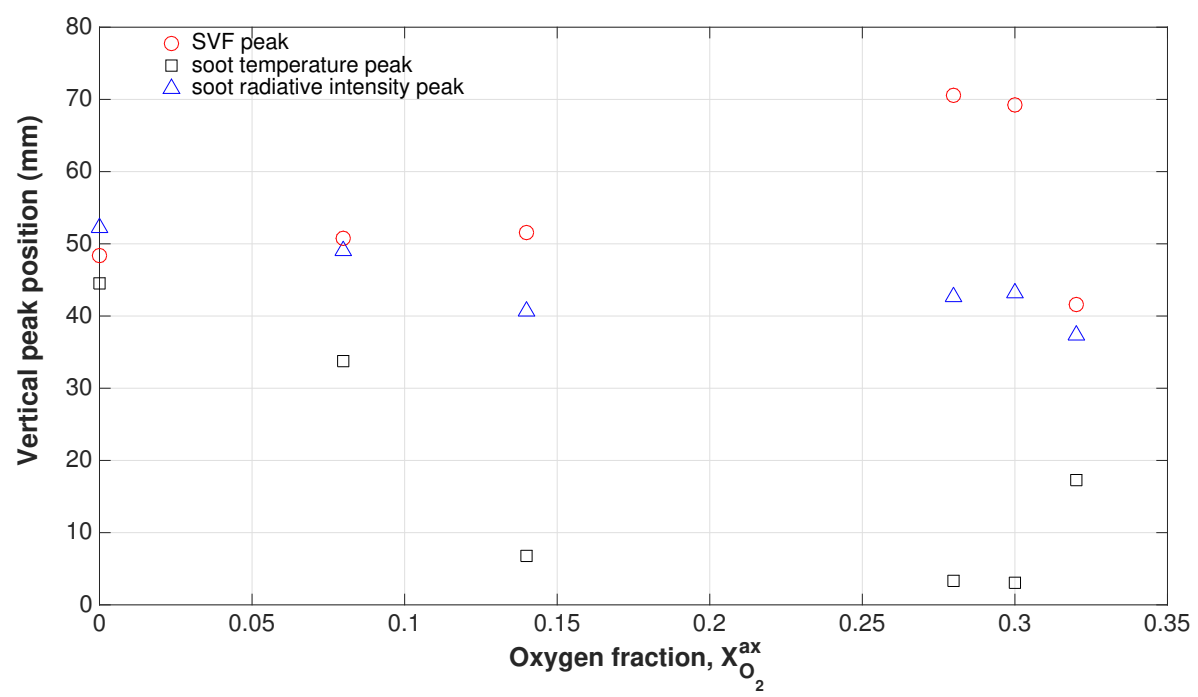

Figure 3: Evolution of the vertical peak positions for oxygen fraction $\left(X_{\mathrm{O}_{2}}^{a x}\right)$ ranging from 0 to $32 \%$. Red circles: SVF peak; black squares: soot temperature peak; blue triangles: soot radiative intensity peak.

almost identical flame central annular position. When the oxygen fraction rises to $30 \%$, the SVF peak position approaches the flame downstream and the SVF field lost the annular structure. In contrast, the soot temperature peak shifts to the flame upstream and a larger temperature gradient is formed in the flame. Interestingly, the flame radiation peak slightly fluctuates between the height 40 and $50 \mathrm{~mm}$ and the topology of the annular structure is restored. This implies that the two factors, i.e., soot temperature and volume fraction together, result in the maximum soot radiative intensity maintaining in flame middle annular region. At $\mathrm{X}_{\mathrm{O}_{2}}^{a x}=32 \%$, these peaks return to flame central annular positions as the initial non-premixed flame, although this flame can be considered as a partial premixed-like flame.

\subsection{Oxygen chemical effect on soot radiative loss}

In the previous studies, the mean cross-section integrated soot volume fraction $F_{\text {soot }}$ was considered as a relevant characteristic of the soot formation and oxidation budget along the flame upward trajectories that soot particles experienced [12, 24], which was defined as:

$$
F_{\text {soot }}(z)=\frac{4}{\pi d_{F}^{2}} \int_{0}^{d_{F} / 2} 2 \pi r S V F(r, z) d r
$$

$F_{\text {soot }}(z)$ represents the visible flame cross-section mean soot volume fraction at a given height $z$ in 
the flame, $\mathrm{d}_{F}=11 \mathrm{~mm}$ being the effective diameter of fuel injection. Similarly, $R_{v}(z)$ is defined here to further quantitatively assess the oxygen chemical effect on the flame soot radiative loss:

$$
R_{v}(z)=\frac{4}{\pi d_{F}^{2}} \int_{0}^{d_{F} / 2} 2 \pi r \mathbf{q}^{R}(r, z) V d r
$$

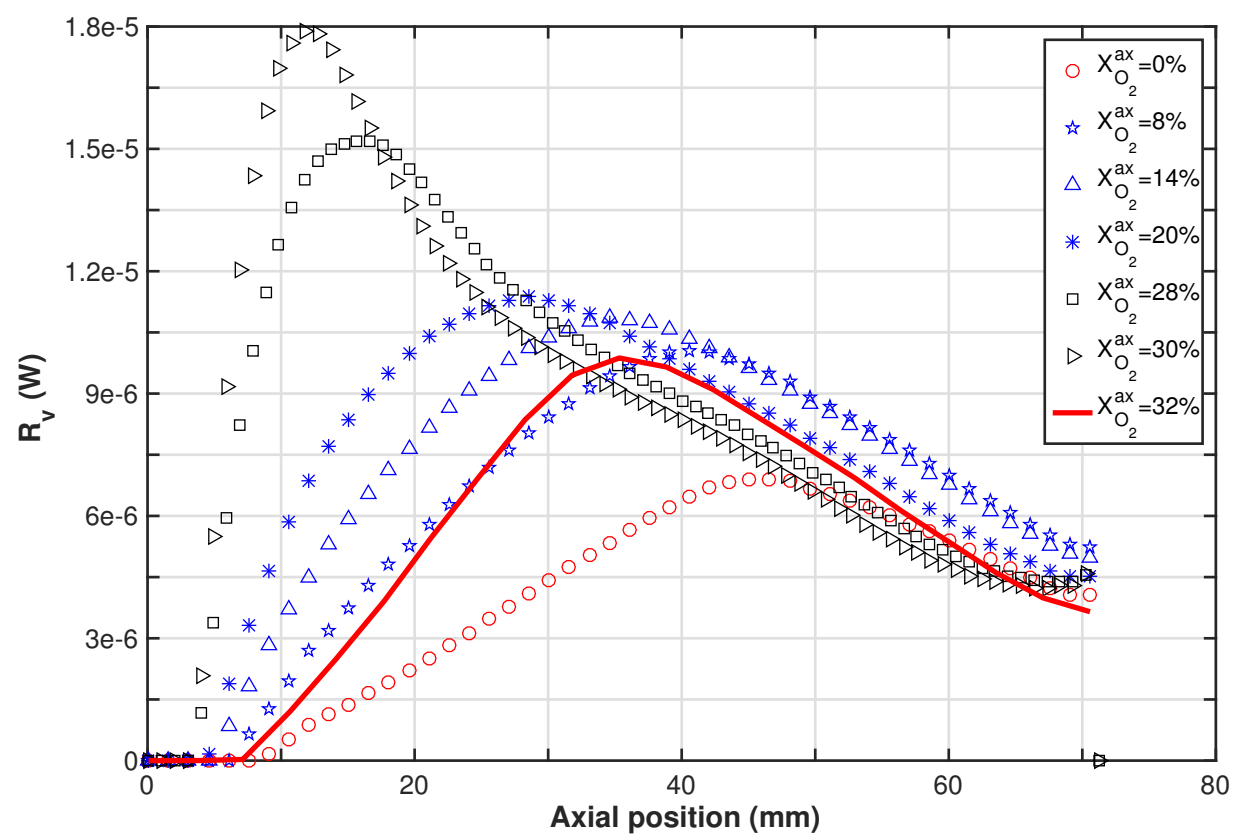

Figure 4: Evolution of the radiative loss $\mathrm{R}_{v}$ attributed to soot along the flame height for different $X_{\mathrm{O}_{2}}^{a x}$ in the fuel stream.

The processed $R_{v}(\mathrm{z})$ profiles with different oxygen fraction $\mathrm{X}_{\mathrm{O}_{2}}^{a x}$ are shown by Fig.4. Compared to that of $F_{\text {soot }}(\mathrm{z})$ in Ref. [16], a similar trend that the maximum of $R_{v}$ approaches to the flame upstream with the increasing of $\mathrm{X}_{\mathrm{O}_{2}}^{a x}$ are found. For $\mathrm{X}_{\mathrm{O}_{2}}^{a x}=32 \%$, the overall flame structure has undergone a sudden change. Furthermore, to isolate the chemical effect of oxygen dilution on soot radiative loss, the soot radiative intensity fields of $\mathrm{N}_{2}$ diluted Santoro flames are also calculated by Eq.(1) and the detailed experimental parameters have been reminded in Tab.1. The detailed $\mathrm{N}_{2}$ diluted soot radiative intensity fields and the corresponding $R_{v}(\mathrm{z})$ profiles with different $X_{N_{2}}^{a x}$ are provided in the APPENDIX B. Selection the peak of $R_{v}(\mathrm{z})$, i.e., $R_{v, \max }$ as the indicator to discriminate the relative radiative loss contributions of the dilution and chemical effects caused by oxygen addition [16]. As a result, the evolution of $\mathrm{R}_{v, \max }$ with varying additive content in the fuel stream is displayed in Fig.5. 


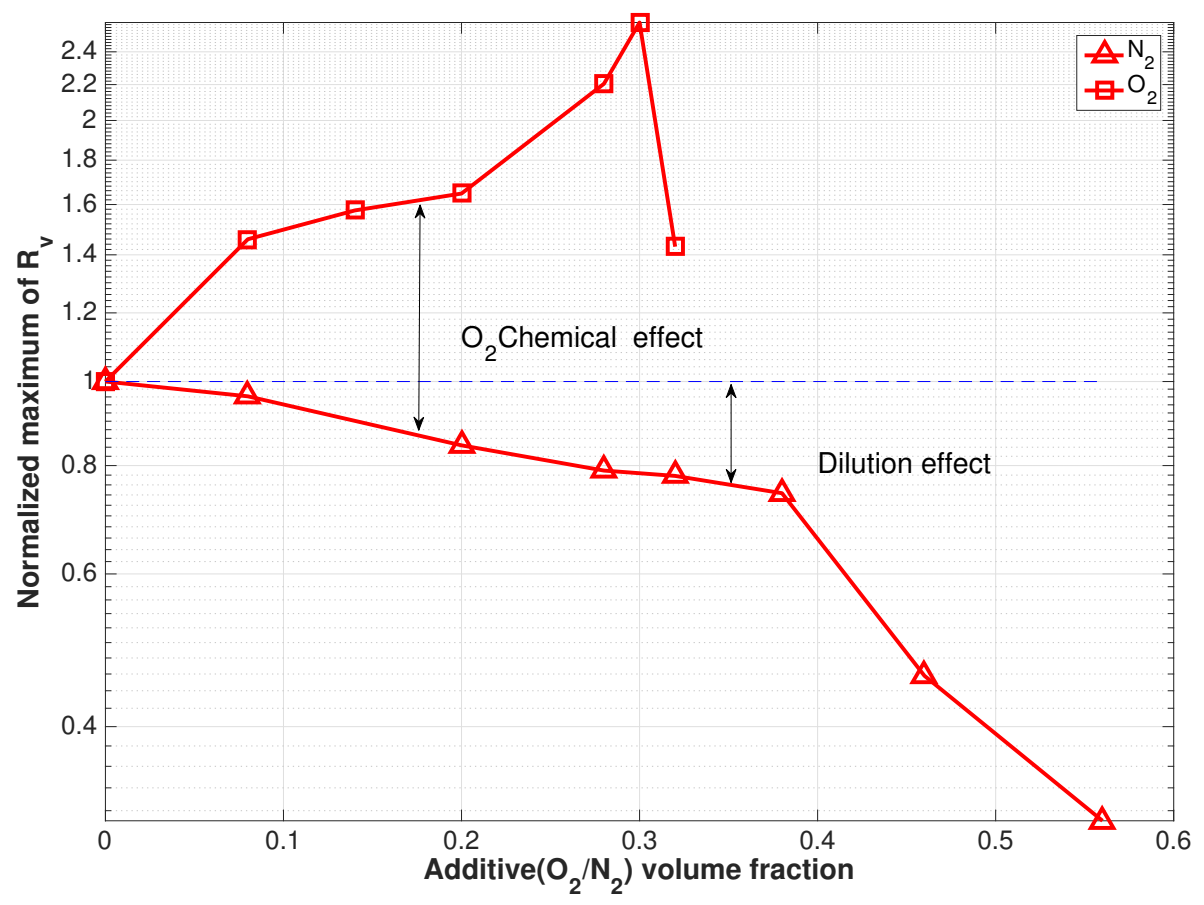

Figure 5: Evolution of the relative dilution and chemical effects by $N_{2}$ and $O_{2}$ on the flame radiative loss attributed to soot. The data are normalized with respect to the undiluted condition.

The magnitude evolution is scaled by the value of $\mathrm{R}_{v, \max }$ for pure ethylene $\left(\mathrm{X}_{\mathrm{O}_{2}}^{a x}=0\right)$ burning in the air, i.e., $\mathrm{R}_{v, \max }=6.6^{*} 10^{-6} \mathrm{~W}$. Here, the baseline is provided by the calculated $\mathrm{R}_{v, \max }$ results from $\mathrm{N}_{2}$ dilution flames. It is worth mentioning that the oxygen chemical effect mainly implies oxygen affecting soot formation due to the direct participation in some chemical pathways of soot formation and oxidation, in addition to the dilution effect and thermal effect introduced by the oxygen additions. In contrast, $\mathrm{N}_{2}$ additions only have the dilution effect and thermal effect. Since oxygen and nitrogen exhibit similar heat capacities and molecular diffusivities, the thermal effect of $\mathrm{N}_{2}$ and $\mathrm{O}_{2}$ are largely canceled out in this relative scale. Therefore, the relative chemical effect of oxygen addition on soot radiative loss can be quantitatively assessed when subtracting the $\mathrm{N}_{2}$ dilution effect. The black arrows illustrate the magnitudes of both effects in Fig.5. As anticipated, the soot radiative loss follows the soot formation trends caused by $\mathrm{N}_{2}$ and $\mathrm{O}_{2}$ dilution. However, compared to the oxygen chemical effect on soot promotion, i.e., the maximum of normalized $\mathrm{F}_{v, \max }$ is 3.3 in Ref. [16], the corresponding oxygen promoted the soot radiative loss is undermined to 2.5 (approx. 25\% reduction). This reduction could be attributed to the large temperature reduction in 
the sooting region. On the other hand, the oxygen dilution effect causes the soot radiation decline, which is the same level of soot formation propensity reduction.

It is noted that these results could further offer new experimental evidence in terms of soot radiative loss to validate the soot oxidation model improvement. For example, Liu et al. [25] numerically studied different cases between fictitious $\mathrm{CO}_{2}$ and normal $\mathrm{CO}_{2}$ to isolated chemical effect in the $\mathrm{CO}_{2}$ diluted ethylene diffusion flames. Therefore, the soot radiative loss due to the chemical effect could be directly compared to that of simulation results.

\subsection{Smoking flames transitions}

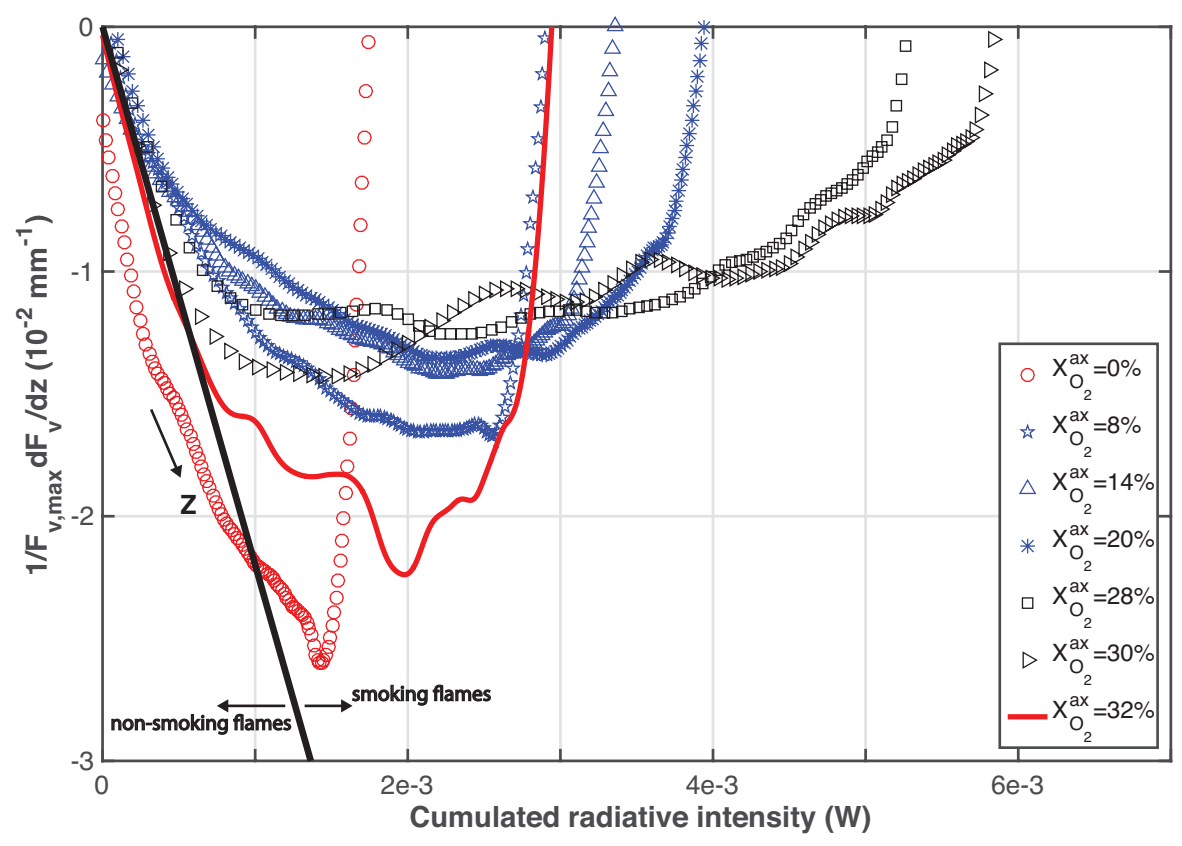

Figure 6: Correlations between the relative soot consumption rate and the soot radiative loss cumulated along the height above the burner $z$ from the location of $z_{F_{v, \text { max }}}$.

Table 2: The experimental fuel velocities, residence times in the seven oxygen diluted flames.

\begin{tabular}{c|ccccccc}
\hline $\begin{array}{c}\text { Coflow } \\
\mathrm{V}_{\text {air }}^{c o} \\
(\mathrm{~L} / \mathrm{min})\end{array}$ & $\begin{array}{c}\mathrm{V}_{\mathrm{C}_{2} H_{4}}^{a x} \\
(\mathrm{~L} / \mathrm{min})\end{array}$ & $\begin{array}{c}V_{O_{2}}^{a x} \\
(\mathrm{~L} / \mathrm{min})\end{array}$ & $\begin{array}{c}\mathrm{O}_{2} \text { diluted fuel flow } \\
(\%)\end{array}$ & $\begin{array}{c}z_{F_{v, \max }} \\
(\mathrm{mm})\end{array}$ & $\begin{array}{c}v^{a x} \\
(\mathrm{~mm} / \mathrm{s})\end{array}$ & $\begin{array}{c}z_{d F_{v} / d z \mid p e a k} \\
(\mathrm{~mm})\end{array}$ & $\begin{array}{c}\tau \\
(\mathrm{s})\end{array}$ \\
\hline \multirow{4}{*}{} & & 0 & 0 & 46 & 40 & 66 & 0.5 \\
& & 0.02 & 8 & 42 & 44 & 62 & 0.45 \\
& & 0.04 & 14 & 38 & 48 & 56 & 0.38 \\
& & 0.06 & 20 & 32 & 50 & 48 & 0.32 \\
& \multirow{4}{*}{0.231} & 0.09 & 28 & 20 & 56 & 35 & 0.27 \\
& & 0.10 & 30 & 14 & 58 & 22 & 0.14 \\
& & 0.11 & 32 & 36 & 60 & 55 & 0.32 \\
\hline
\end{tabular}


To trace the smoking flames transition, the relative soot consumption rate $1 / \mathrm{F}_{v, \max } \mathrm{dF}_{v} / \mathrm{dz}$ can be correlated at every $z$ beyond the location $z_{F_{v, \text { max }}}$ with the soot radiative loss that cumulated between $z_{F_{v, \max }}$ and $z$. The locations of $z_{F_{v, \text { max }}}$ variations with $\mathrm{X}_{\mathrm{O}_{2}}^{a x}$ that extracted from the Ref.[16] are summarized in Tab.2. Furthermore, because the air coflow keeps constant, the oxygen is incrementally added to the central fuel flow, the corresponding central fuel flow velocities $v^{a x}$ are calculated as well. Since the soot oxidation is assumed to dominate the soot formation beyond the location of $z_{F_{v, \text { max }}}$, the trend lines in Fig.6 imply the soot radiative loss due to relative soot oxidation from the position of $z_{F_{v, \max }}$. It is noted that there exists a soot consumption rate peak in every trend line, by which the trend line splits into two parts. The peak locations $z_{d F_{v} / d z \mid p e a k}$ in the every trend lines are listed in the Tab.2 as well. The peak location indicates that the place where soot consumption rate begins to turn weak and eventually decays to zero, along with the higher cumulated soot radiative loss. Thus, the residence time $\tau$ that accounted from the location of $z_{F_{v, \text { max }}}$ to the location of $z_{d F_{v} / d z \mid \text { peak }}$ could be estimated by $\left(z_{d F_{v} / d z \mid \text { peak }}-z_{F_{v, \max }}\right) / v^{a x}$ and the results are shown in the last column of Tab.2.

For the first transition $\mathrm{X}_{\mathrm{O}_{2}}^{a x}$ from 0 to $8 \%$, the steepness reduction of the first part of trend line indicates the oxidation process becomes weak, and the residence time is shorter, along with cumulated soot radiative loss approaching higher level in the second part of the trend line, which ultimately causes soot escaping and the flame transits from non-smoking to smoking. On the contrary, for the flame of $\mathrm{X}_{\mathrm{O}_{2}}^{a x}=0 \%$, a larger relative soot oxidation rate maintains a long time until it reaches the peak. It followed by a steep consumption rate reduction to zero, which is probably attributed to the vanishing of the soot. Therefore, less soot radiative loss is cumulated and the total soot is completely oxidized beneath the flame tip.

For $\mathrm{X}_{\mathrm{O}_{2}}^{a x}$ from $8 \%$ to $30 \%$, the soot oxidation undergoes a more complicated transformation, which could be divided into two stages. From $8 \%$ to $20 \%$ (blue scatters), the steepness of the first part trend line continues reducing, which implies the initial relative soot oxidation rate further decrease and results in more soot escapes from the flame and higher soot radiative loss. This is probably attributed to the temperature reduction at the position of $z_{F_{v, \max }}$, as the temperature peak rapidly shifts to the flame upstream. In the second stage, for $\mathrm{X}_{\mathrm{O}_{2}}^{a x}$ from 28 to $30 \%$ (black scatters), the steepness of first part trend line returns a bit high; thus, the initial relative soot 
oxidation rate turns stronger, it quickly reaches the peak and gently declines to zero. It results in

even more higher soot emission and radiative loss, since the position of $z_{F_{v, \max }}\left(14 \mathrm{~mm}\right.$ at $\mathrm{X}_{\mathrm{O}_{2}}^{a x}=$ $30 \%$ in Tab.2) approaches the temperature peak located at lower position, i.e., $z=4 \mathrm{~mm}$ at $\mathrm{X}_{\mathrm{O}_{2}}^{a x}=$ $30 \%$ (see in Fig.3).

As expected, for the second transition at $\mathrm{X}_{\mathrm{O}_{2}}^{a x}=32 \%$, the steepness of the first part trend line becomes steeper. Though it is lower than that of $\mathrm{X}_{\mathrm{O}_{2}}^{a x}=0 \%$, due to enough higher relative oxidation rate and long residence time in the first part of trend line, the soot is also completely consumed and flame shifts back to the non-smoking flame. Interestingly, the second part of the trend line is almost identical to that of $\mathrm{X}_{\mathrm{O}_{2}}^{a x}=8 \%$, it further indicates that the initial relative oxidation rate and the residence time are two important factors that may affect the soot oxidation process and the final soot smoking/non-smoking transition characteristics. As a result, the black line delineates the non-smoking flames and smoking flames region in terms of the steepness of the first part trend line, namely, the initial relative oxidation rate.

It is noted that Bonnety et al. [12] computed the soot radiative field to track the flame smoking transition and offered soot oxidation quenching evidence due to the soot radiative loss on the flame tip region. In the present study, we indeed focus on the flame region below the tip, i.e. from 0 to 70 $\mathrm{mm}$, the total Santoro flame $\left(\mathrm{X}_{\mathrm{O}_{2}}^{a x}=0\right)$ height reaches about $100 \mathrm{~mm}$. And the present investigated flames could be treated as the extension of previous studies by Bonnety, since this study tracked the development of the heavy sooting flames $\left(\mathrm{SVF}_{\max }\right.$ up to $55 \mathrm{ppm}$ detailed in Tab.1) and the processes of the transition characteristics in smoking/non-smoking flames.

\section{Conclusion}

In this study, the radiative characteristics of oxygen diluted heavy sooting Santoro flames are extensively investigated. The soot radiative intensity fields are presented by the solution of the RTE. Along with the oxygen fraction rising from 0 to $32 \%$, the soot total radiative and peak radiative intensity undergo only one remarkable transition between $\mathrm{X}_{\mathrm{O}_{2}}^{a x} 30 \%$ and $32 \%$ during the two significant smoking/non-smoking transition processes. And the soot spectral radiation proportion within the total flame spectral radiation rises from 0.78 to 0.91 and followed by a reduction at $\mathrm{X}_{\mathrm{O}_{2}}^{a x}$ $=32 \%$. Though the soot temperature and volume fraction fields of oxygen diluted flames experience 
significant transitions in the topology, the peaks of soot radiative intensity fields remain at the flame annular position.

Moreover, the oxygen chemical effect on the soot radiative loss is further isolated and found that the oxygen chemical effect largely promotes the soot radiative loss in flames, however, due to the temperature reduction in the sooting region, this effect is undermined by approximately $25 \%$. In contrast, the oxygen dilution effect results in a similar reduction level on soot formation propensity and soot radiative loss.

Eventually, the heavy sooting flame transition characteristics are explored in terms of the relative consumption rate variation with the cumulated radiative loss. The results imply that the initial relative oxidation rate at the position of $z_{F_{v, \text { max }}}$ and its residence time may affect the soot evolution in the flame tip, therefore influencing the flame smoking/non-smoking transition.

\section{Acknowledgments}

The present study has been supported by the Natural National Science Foundation of China (NSFC) (51706140, 51922076).

\section{Reference}

[1] H. Michelsen, Probing soot formation chemical and physical evolution and oxidation: A review of in situ diagnostic techniques and needs, Proc. Combust. Inst. 36 (2017) 1-19.

[2] Z. Sun, B. Dally, Z. Alwahabi, G. Nathan, The effect of oxygen concentration in the co-flow of laminar ethylene diffusion flames, Combust. Flame 211 (2020) 96-111.

[3] C. M. Megaridis, R. A. Dobbins, Soot aerosol dynamics in a laminar ethylene diffusion flame, Proc. Combust. Inst. 22 (1989) 353-362.

[4] M. D. Smooke, M. B. Long, B. C. Connelly, M. B. Colket, R. J. Hall, Soot formation in laminar diffusion flames, Combust. Flame 143 (2005) 613-628.

[5] S. B. Dworkin, Q. Zhang, M. J. Thomson, N. A. Slavinskaya, U. Riedel, Application of an enhanced PAH growth model to soot formation in a laminar coflow ethylene/air diffusion flame, Combust. Flame 158 (2011) 168-1695.

[6] G. H. Markstein, Relationship between smoke point and radiant emission from buoyant turbulent and laminar diffusion flames, Proc. Combust. Inst. 20 (1985) 1055-1061.

[7] I. Glassman, Combustion, 3rd ed., Academic Press (1996) 407-409.

[8] S. T. Sunderland, S. Mortazavi, G. M. Faeth, D .L. Urban, Laminar smoke points of nonbuoyant jet diffusion flames, Combust. Flame 96 (1994) 97-103.

[9] R. J. Watson, M. L. Botero, C. J. Ness, N. M. Morgan, M. Kraft, An improved methodology for determining threshold sooting indices from smoke point lamps, Fuel 111 (2013) 120-130. 
[10] R. J. Santoro, T. T. Yeh, J. J. Horvath, H. G. Semerjian, The Transport and Growth of Soot Particles in Laminar Diffusion Flames, Combust. Sci. Technol. 53 (1987) 89-115.

[11] C. M. Megaridis, R. A. Dobbins, Comparison of soot growth and oxidation in smoking and non-smoking ethylene diffusion flames, Combust. Sci. Technol. 66 (1989) 1-16.

[12] J. Bonnety, A. Guibaud, R. Jalain, A. Matynia, J.-L. Consalvi, F. Liu, G. Legros, Probing the local radiative quenching during the transition from a non-smoking to a smoking laminar coflow ethylene/air non-premixed flame, Combust. Flame 203 (2019) 120-129.

[13] F. Liu, H. Guo, G. J. Smallwood, Ö. Gülder, Numerical modelling of soot formation and oxidation in laminar coflow non-smoking and smoking ethylene diffusion flames, Combust. Theor. Model. 7 (2003) 301-315.

[14] A. Veshkini, S. B. Dworkin, M. J. Thomson, A soot particle surface reactivity model applied to a wide range of laminar ethylene/air flames, Combust. Flame 161 (2014) 3191-3200.

[15] A. Khosousi, S. B. Dworkin, Soot surface reactivity during surface growth and oxidation in laminar diffusion flames, Proc. Combust. Inst. 35 (2015) 1903-1910.

[16] Q. Wang, G. Legros, J. Bonnety, C. Morin, A. Matynia, J.-L. Consalvi, F. Liu, Experimental assessment of the sudden-reversal of the oxygen dilution effect on soot production in coflow ethylene flames, Combust. Flame 183 (2017) 242-252.

[17] Q. Wang, G. Legros, J. Bonnety, C. Morin, Experimental characterization of the different nitrogen dilution effects on soot formation in ethylene diffusion flames, Proc. Combust. Inst. 36 (2017) 3227-3235.

[18] G. Legros, Q. Wang, J. Bonnety, M. Kashif, C. Morin, J.-L. Consalvi, F. Liu, Simultaneous soot temperature and volume fraction measurements in axis-symmetric flames by a two-dimensional modulated absorption/emission technique, Combust. Flame 162 (2015) 2705-2719.

[19] H. Chang, T. T. Charalampopoulos, Determination of the wavelength dependence of refractive indices of flame soot, Proc. Roy. Soc. Lond. A 430 (1990) 577-591.

[20] E. H. Chui, G. D. Raithby, P. M. J. Hughes , Prediction of radiative transfer in cylindrical enclosures with the finite volume method, J. Thermophys. Heat Transf. 6 (1992) 605-611.

[21] R. Demarco, F. Nmira, J. L. Consalvi, Influence of thermal radiation on soot production in laminar axisymmetric diffusion flames, J. Quant. Spectrosc. Radiat. Transf. 120 (2013) 52-69.

[22] D.R. Snelling, F. Liu, G.J. Smallwood, .L. Glder, Determination of the soot absorption function and thermal accommodation coefficient using low-fluence LII in a laminar coflow ethylene diffusion flame, Combust. Flame $136,(2004)$ 180-190.

[23] H.A. Michelsen, Understanding and predicting the temporal response of laser-induced incandescence from carbonaceous particles, J. Chem. Phys. 118, (2003) 7012-7045.

[24] M. Kashif, P. Guibert, J. Bonnety, G. Legros, Sooting tendencies of primary reference fuels in atmospheric laminar diffusion flames burning into vitiated air, Combust. Flame 161 (2014) 1575-1586.

[25] F. S. Liu, H. S. Guo, G. J. Smallwood, The chemical effects of carbon dioxide as an additive in an ethylene diffusion flame: Implications for soot and NOx formation, Combust. Flame 125 (2001) 778-787. 


\section{APPENDIX A: $\mathrm{E}(\mathrm{m})$ model influence}

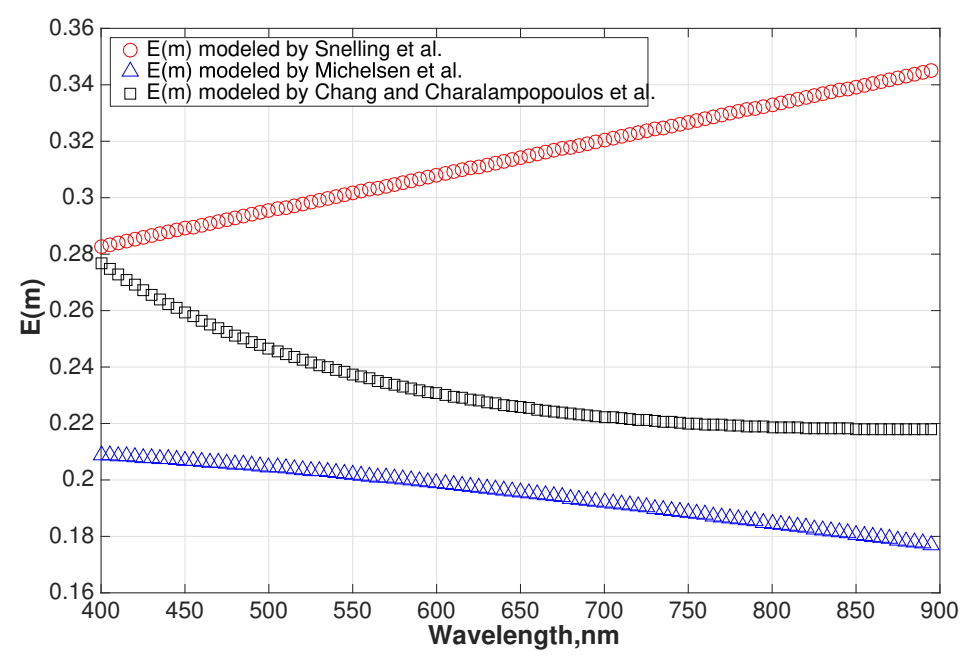

Figure 7: Evolutions of the $\mathrm{E}(\mathrm{m})$ with the wavelength in three models

Since the $\mathrm{E}(\mathrm{m})$ model of the soot refractive index is a controversial domain, the possible $\mathrm{E}(\mathrm{m})$ model influence on the soot radiative fields calculation by the Eq.(1) is investigated. To this end, two extreme $\mathrm{E}(\mathrm{m})$ models are added for comparison. One is the increasing model provided by Snelling et al. [22]. Another is a decreasing model that given for the solid graphite [23]. The detailed E(m) model variations with wavelength are displayed in Fig.7.

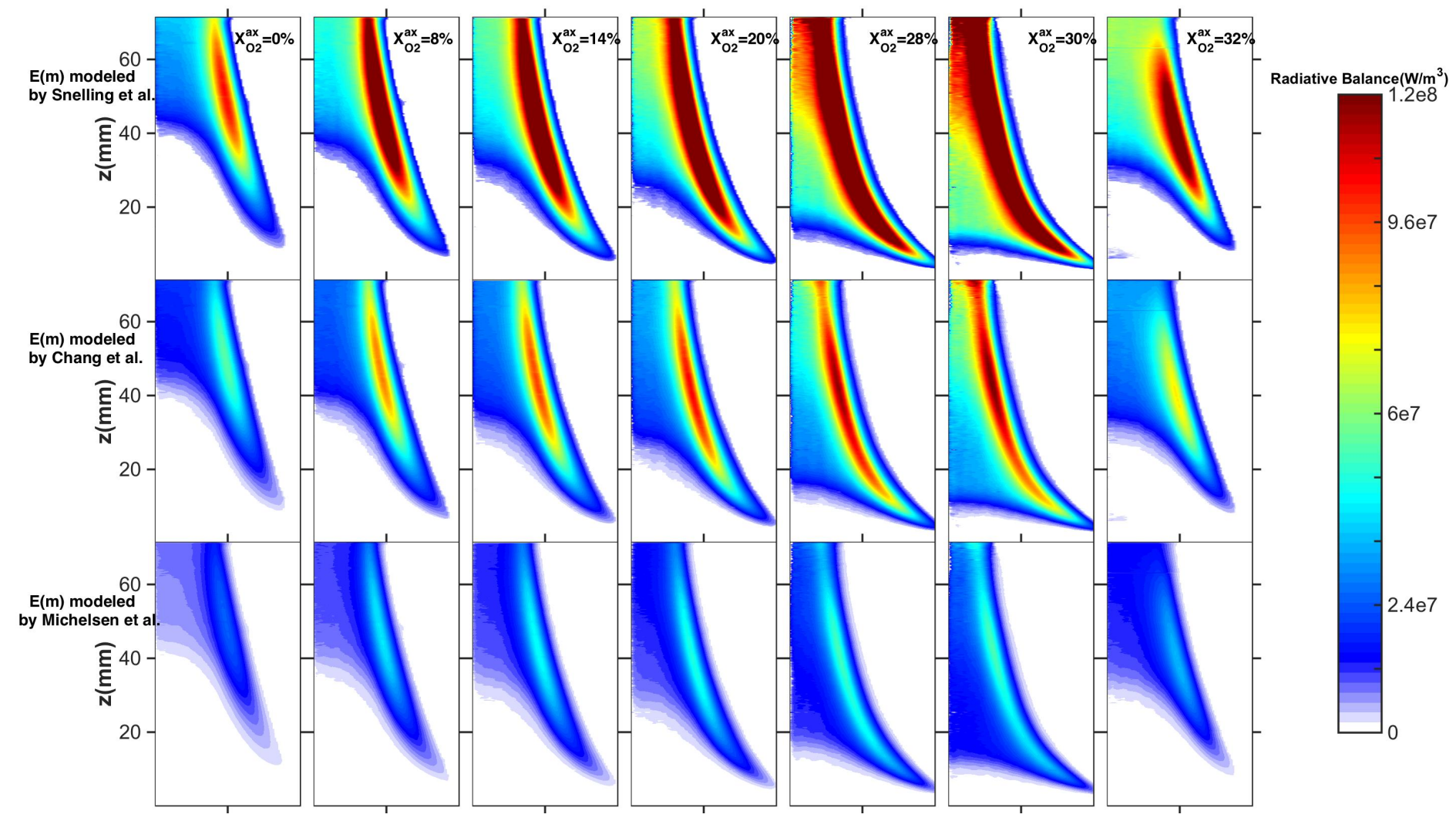

Figure 8: The calculated soot radiative fields variations with the oxygen fraction by three $\mathrm{E}(\mathrm{m})$ models. Top row: $\mathrm{E}(\mathrm{m})$ modeled by Snelling et al. [22]; middle row: E(m) modeled by Chang \& Charalampopoulos et al. [19]; bottom row: $\mathrm{E}(\mathrm{m})$ modeled by Michelsen et al. [23] 
As a result, the Fig. 8 shows the calculated soot radiative fields variations with the oxygen fraction by three $\mathrm{E}(\mathrm{m})$ models. As anticipated, the calculated soot radiative fields' absolute magnitudes vary with the magnitudes of E(m). Yet, the transition trend with the oxygen fraction is unchanged. Fig.9 shows the normalized soot peak radiative intensity evolution with the oxygen fraction for the three $\mathrm{E}(\mathrm{m})$ models. It indicates that the model of $\mathrm{E}(\mathrm{m})$ has a trivial influence on the relative amplitudes of soot radiative intensities within the oxygen fraction variations; thus, the $\mathrm{E}(\mathrm{m})$ uncertainties do not affect the conclusions in the present paper.

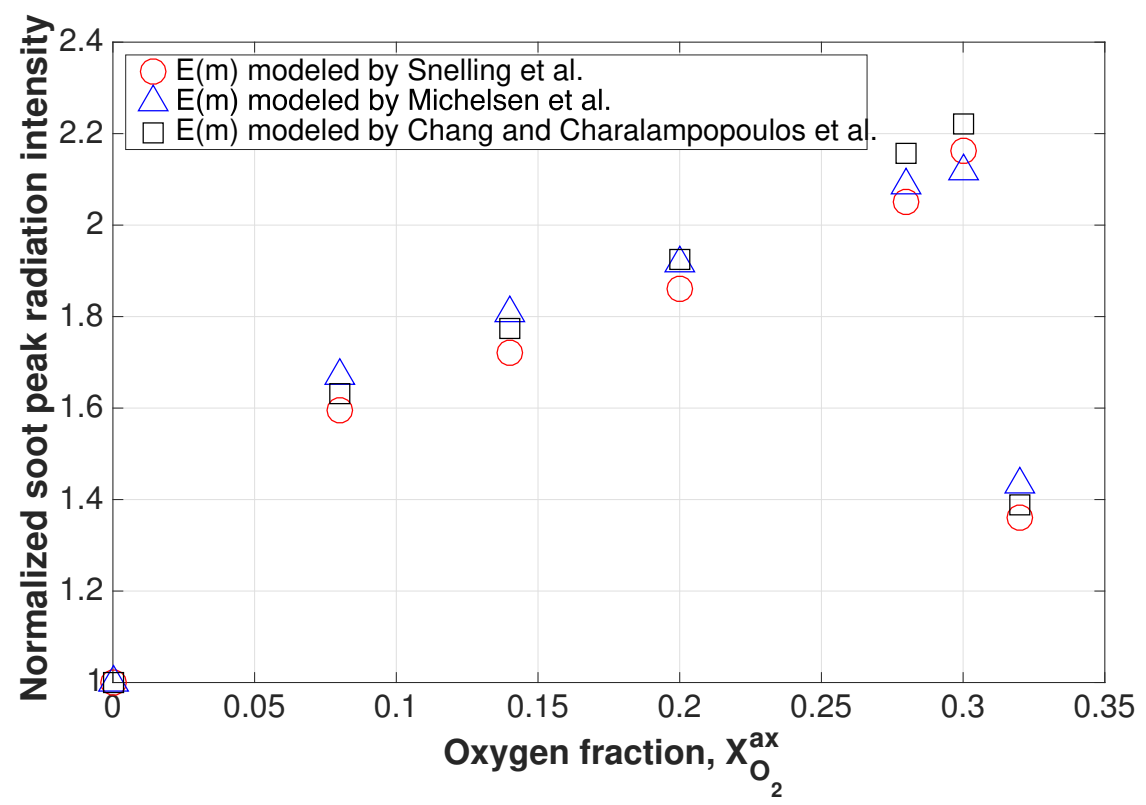

Figure 9: The normalized soot peak radiation intensity evolution with the oxygen fraction for the three models. All the data (open scatters) are normalized by their value at $X_{\mathrm{O}_{2}}^{a x}=0$

\section{APPENDIX B}



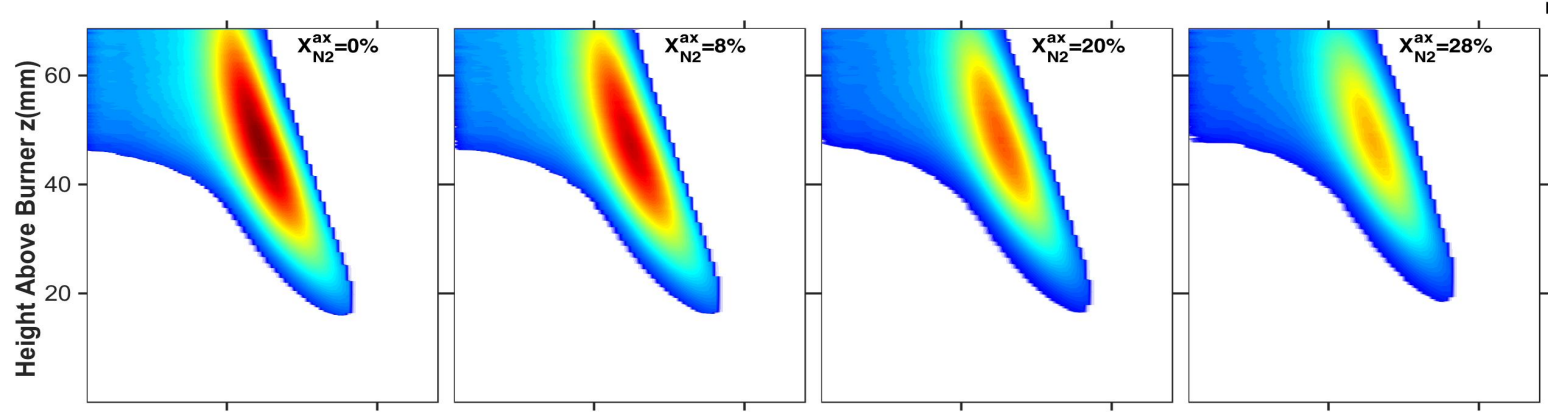

Radiative balance, $\mathbf{W} / \mathrm{m}^{3}$
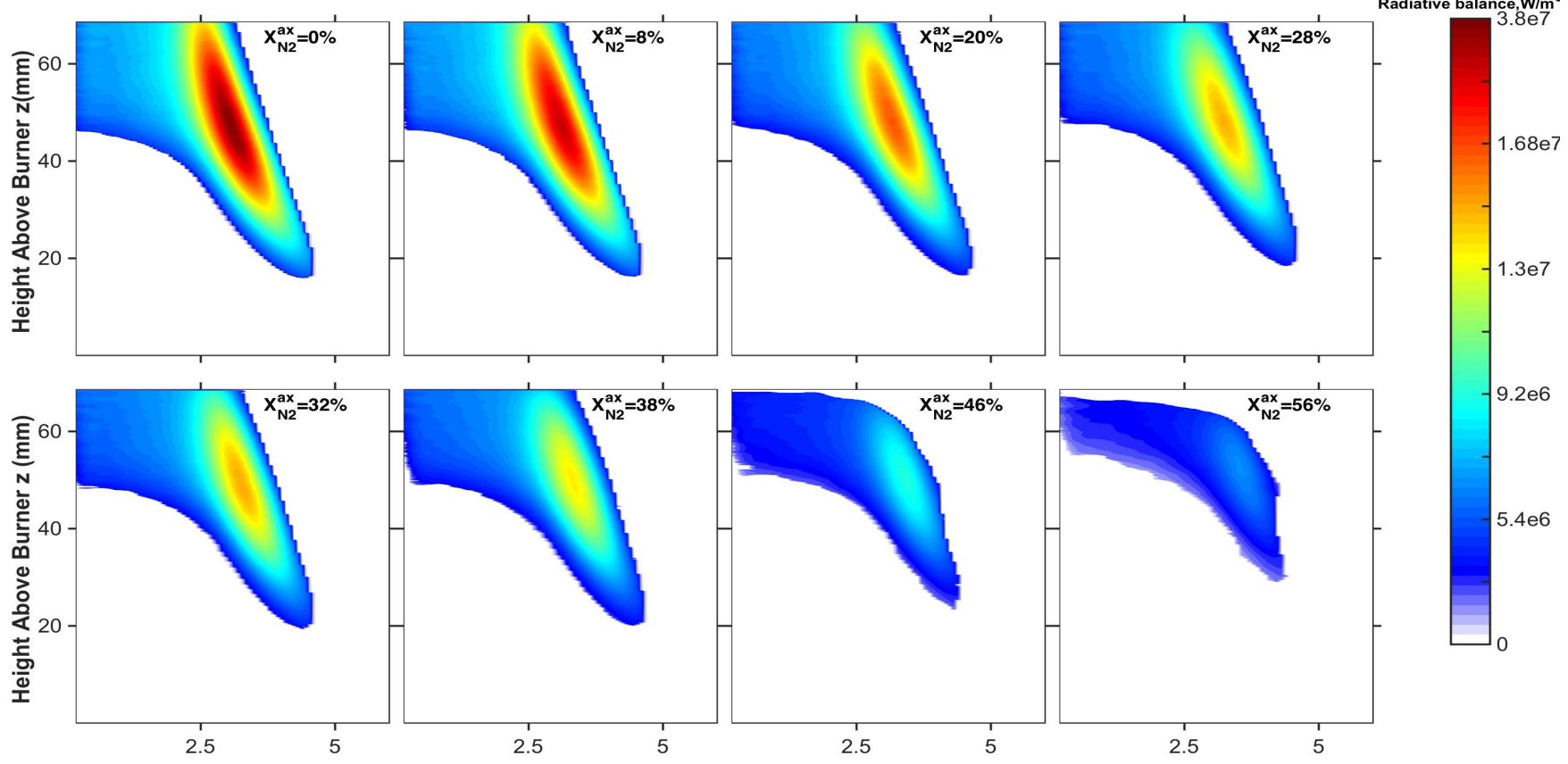

Figure 10: Local soot radiative fields computed from the experimental local soot volume fraction and temperature fields for oxygen fraction $\left(X_{N_{2}}^{a x}\right)$ ranging from 0 to $56 \%$ in the central stream. The experimental local soot volume fraction and temperature fields come from Ref.[17].

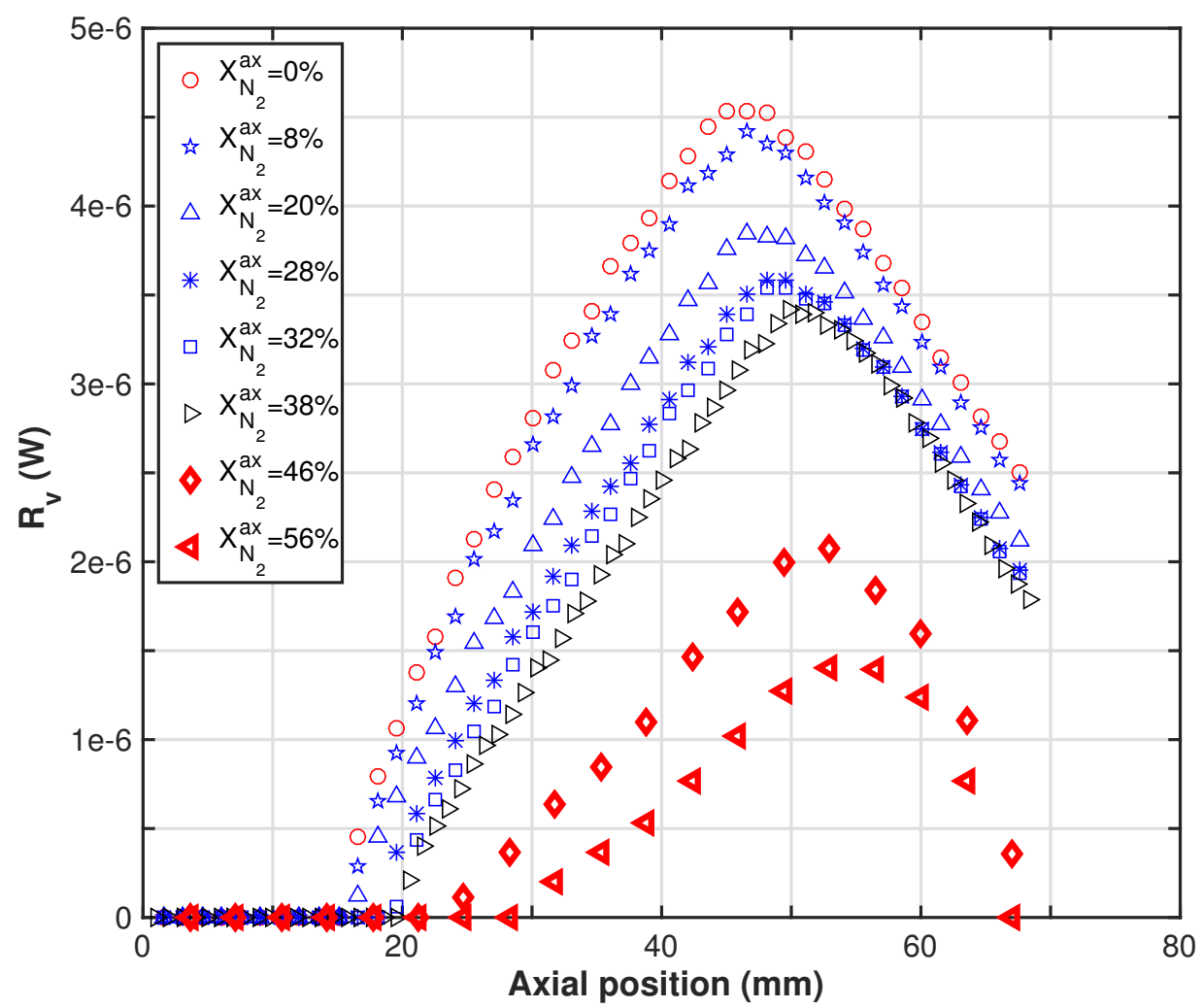

Figure 11: Evolution of the radiative loss $\mathrm{R}_{v}$ attributed to soot along the flame height for different $X_{N_{2}}^{a x}$ in the fuel stream. 


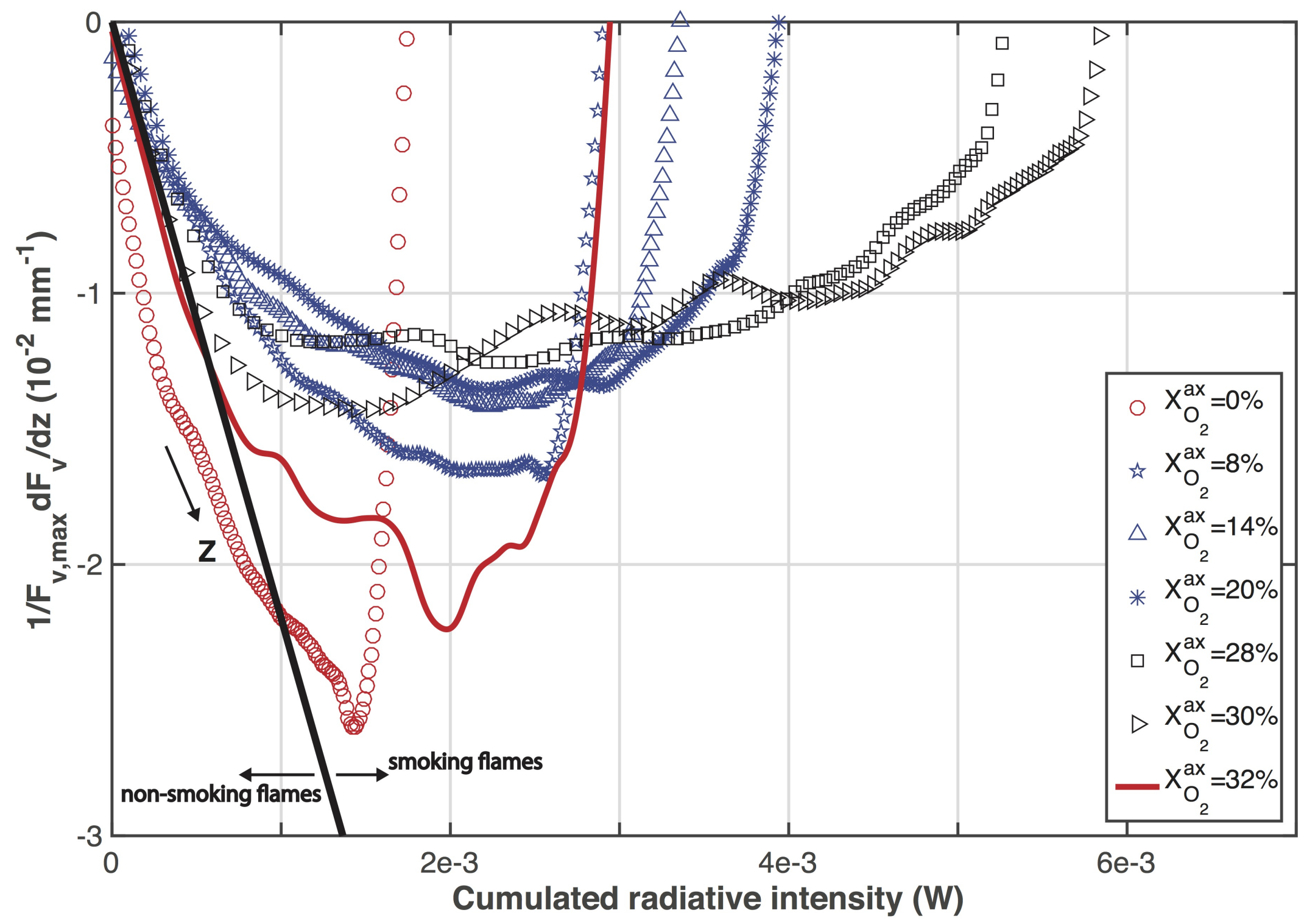




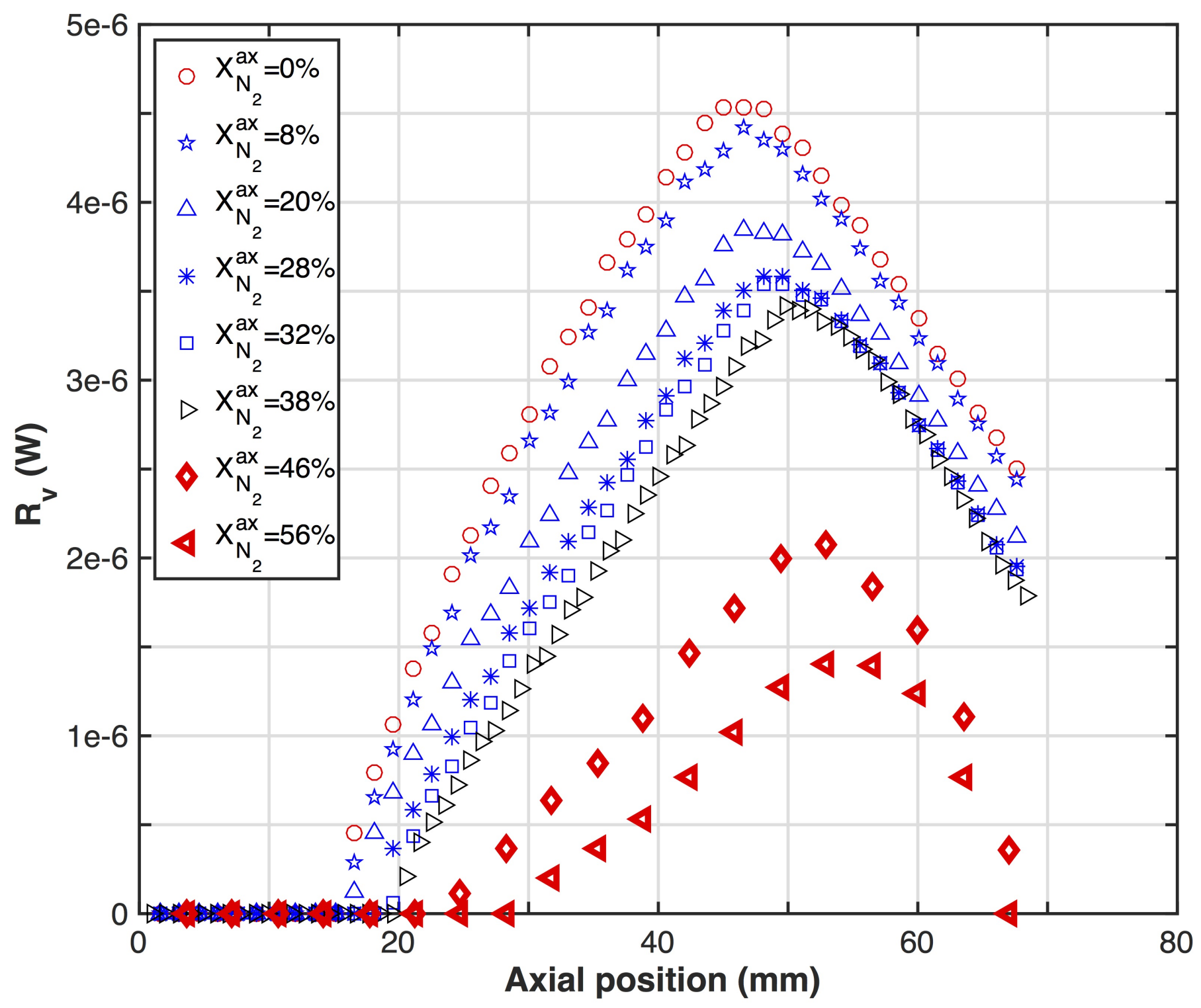




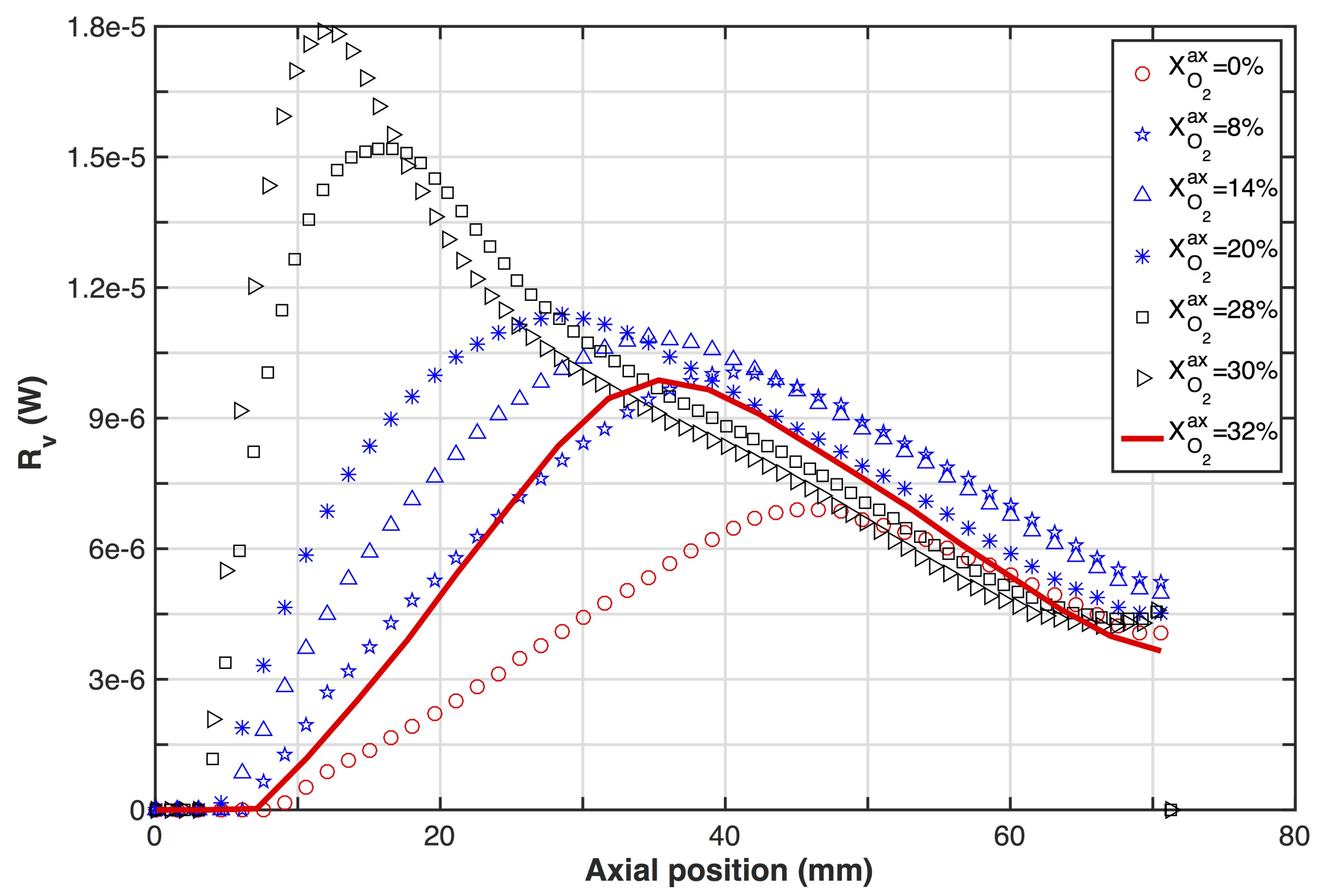




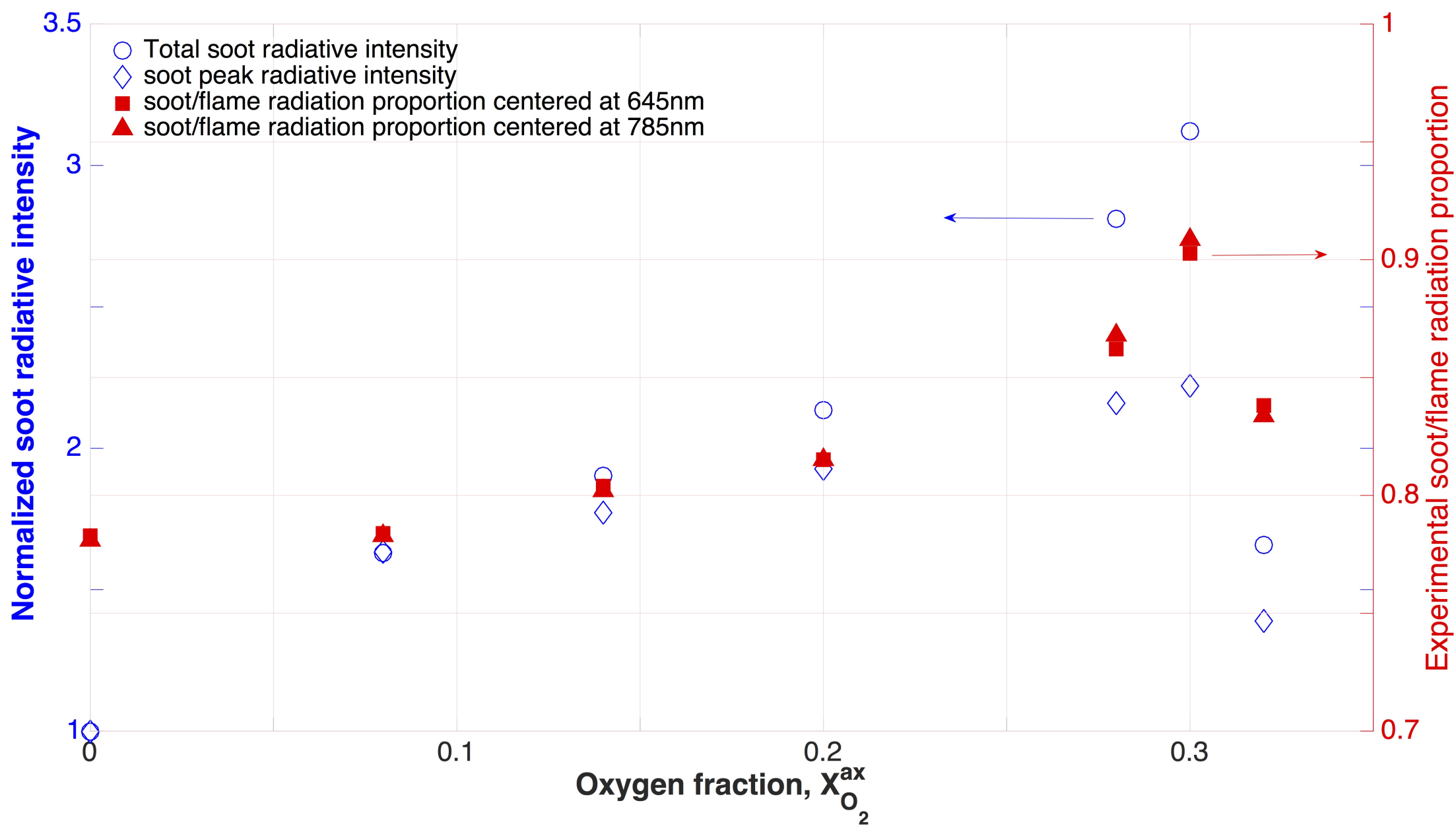




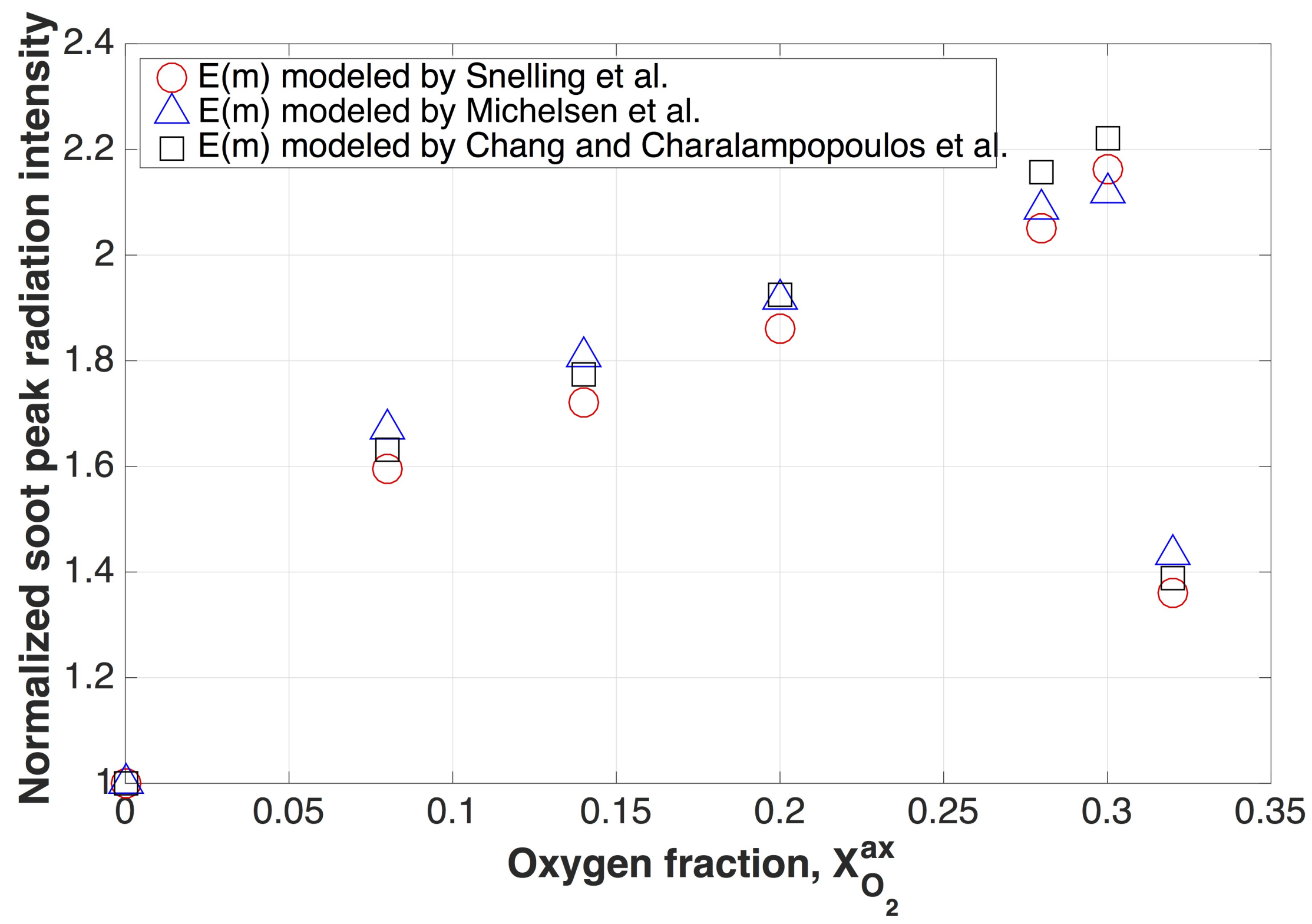




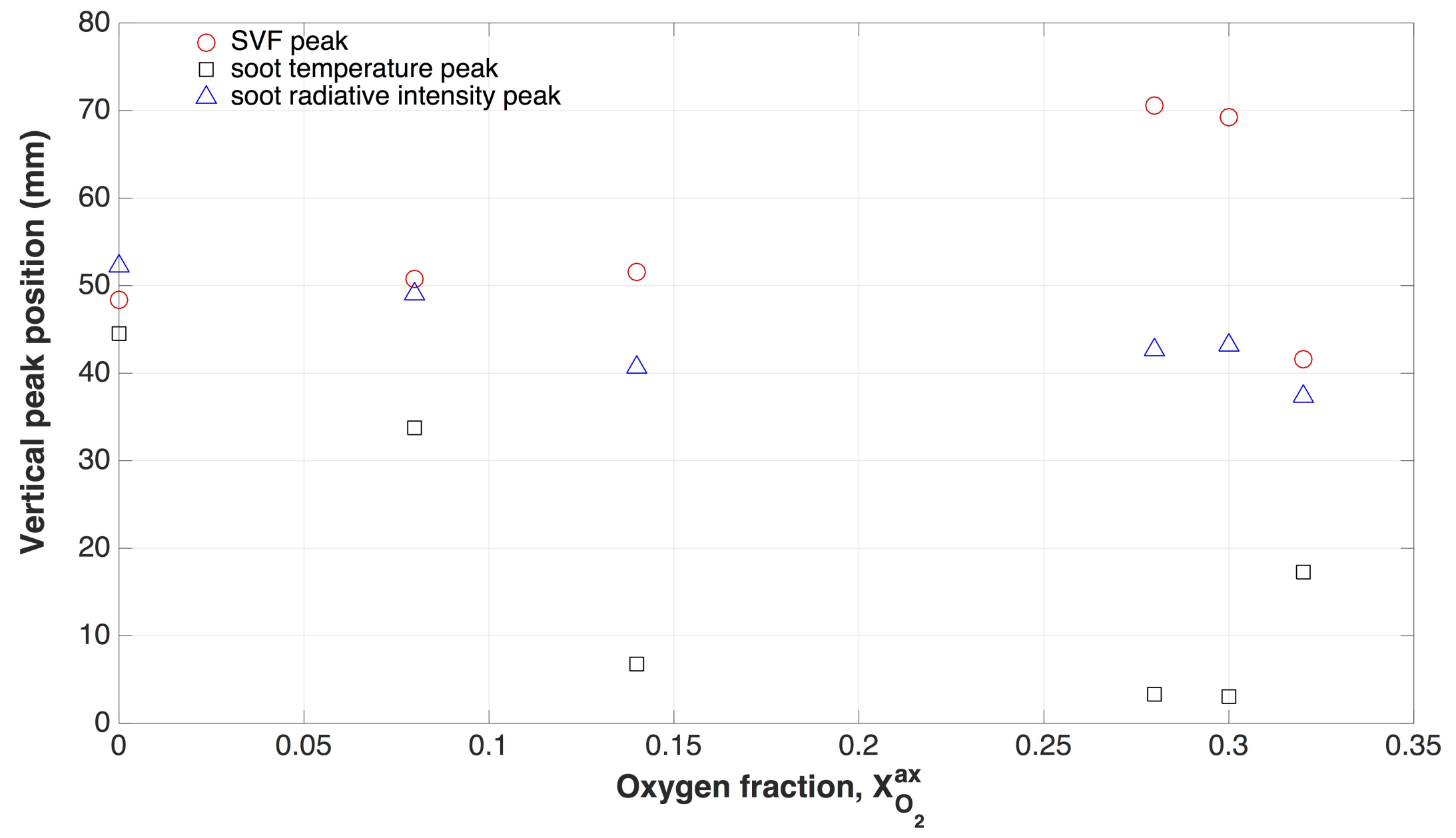




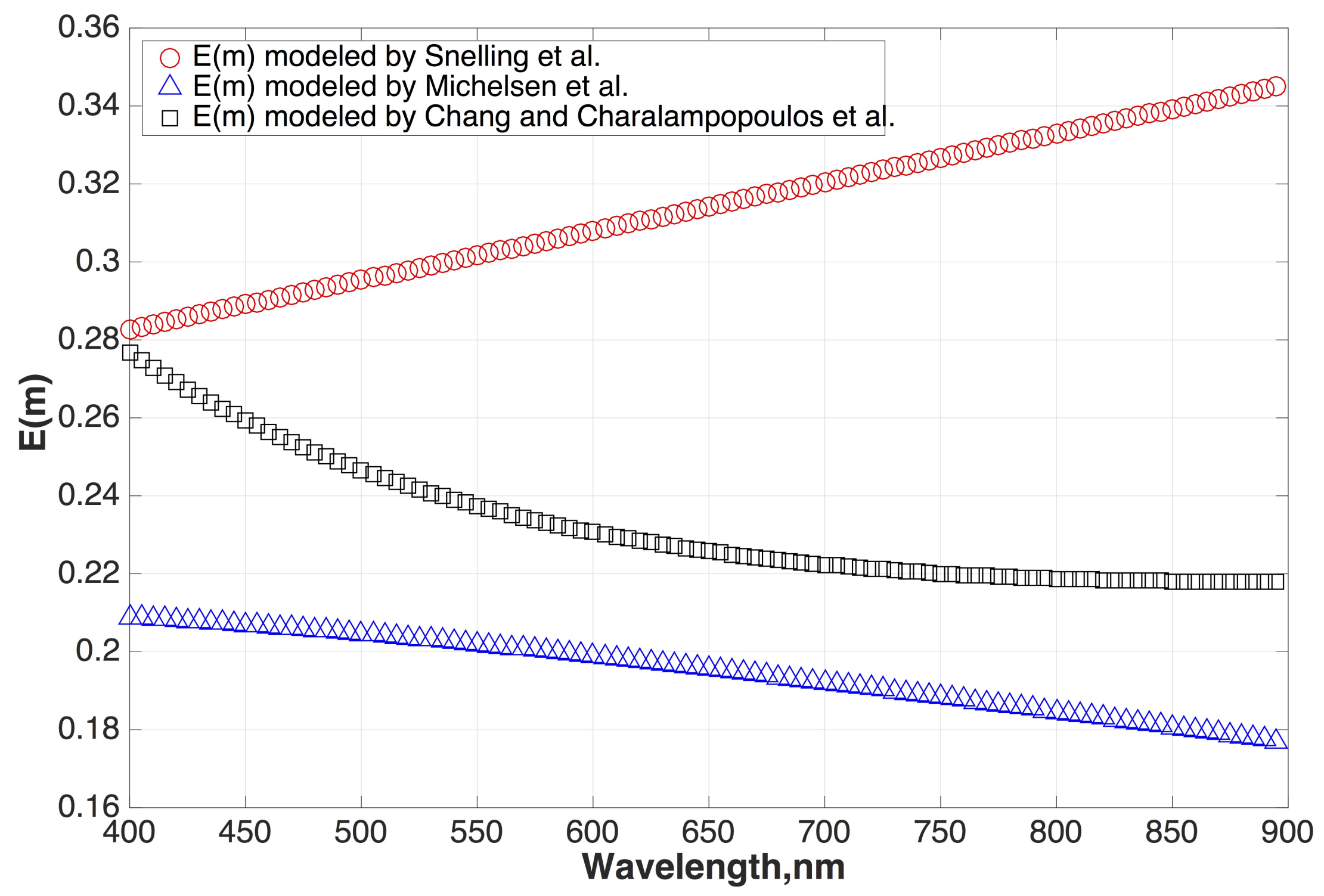




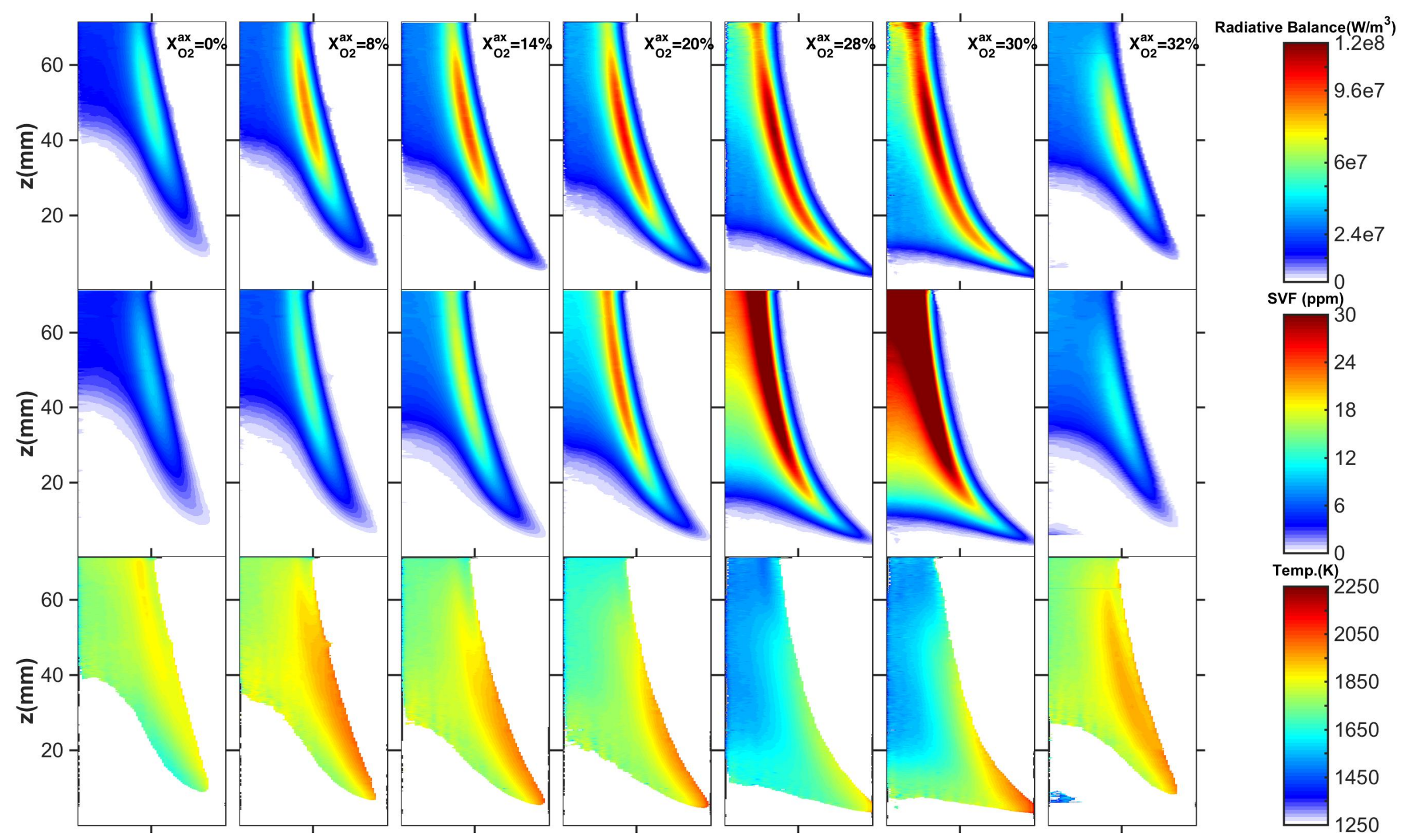




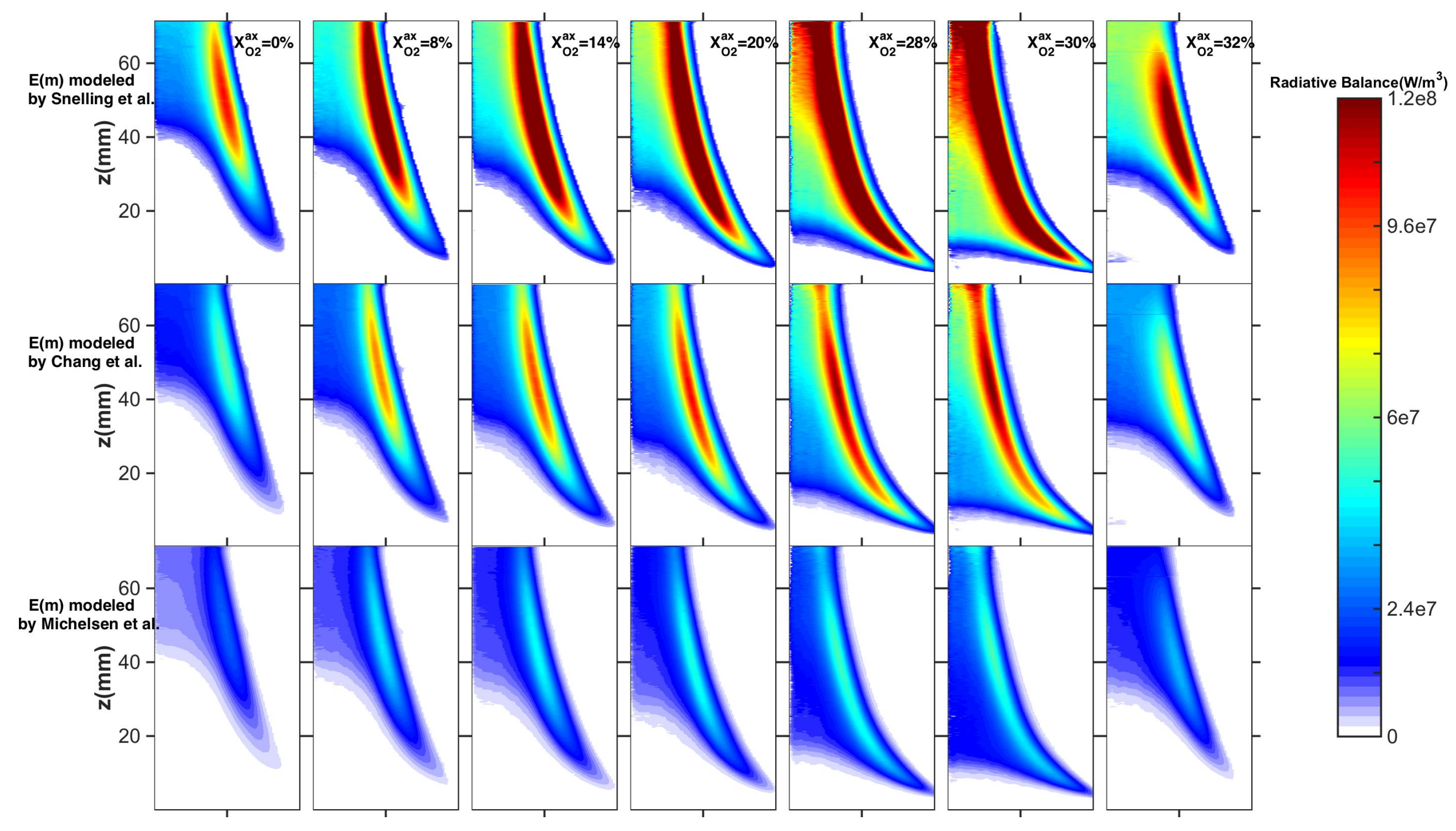




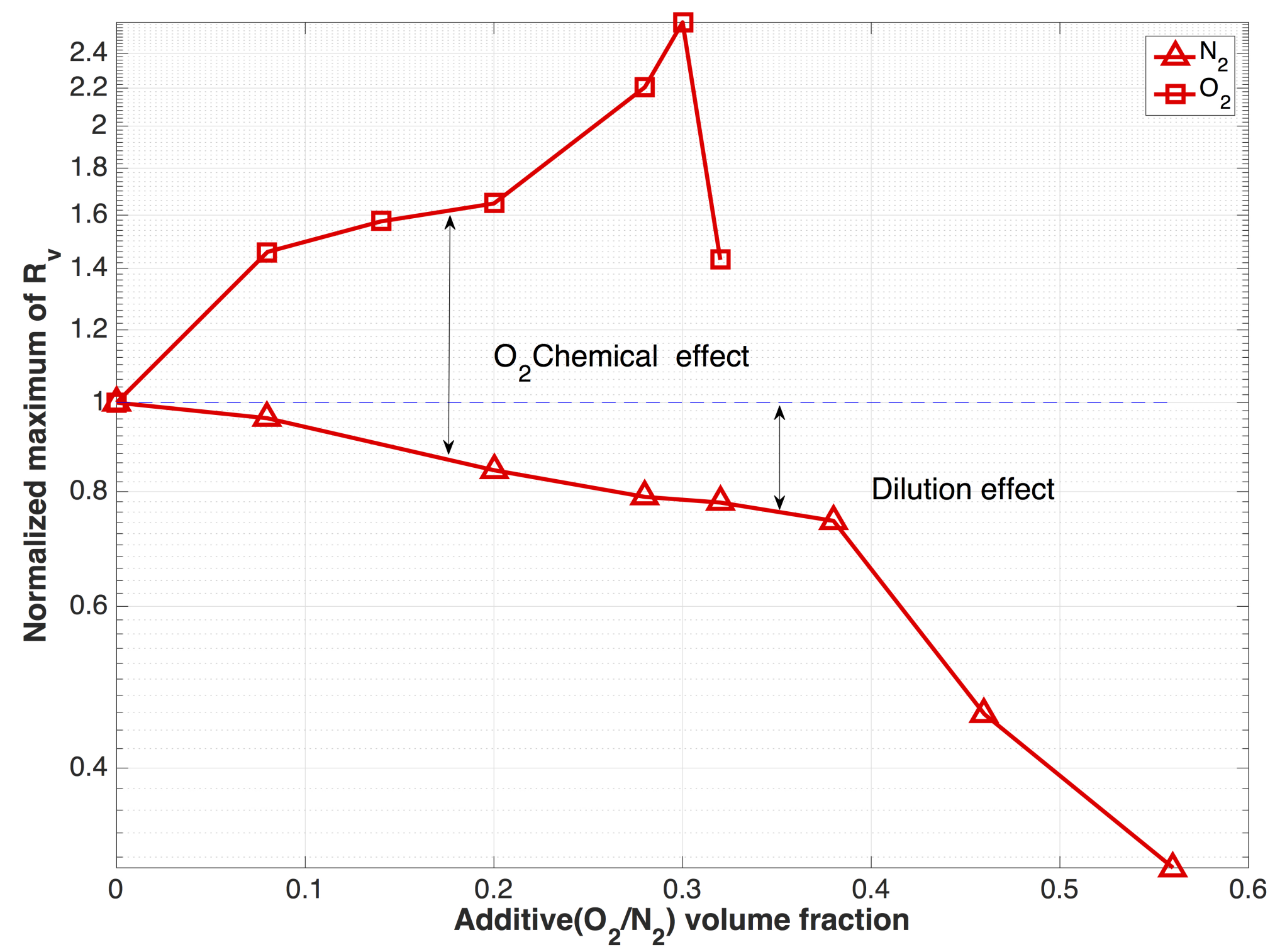



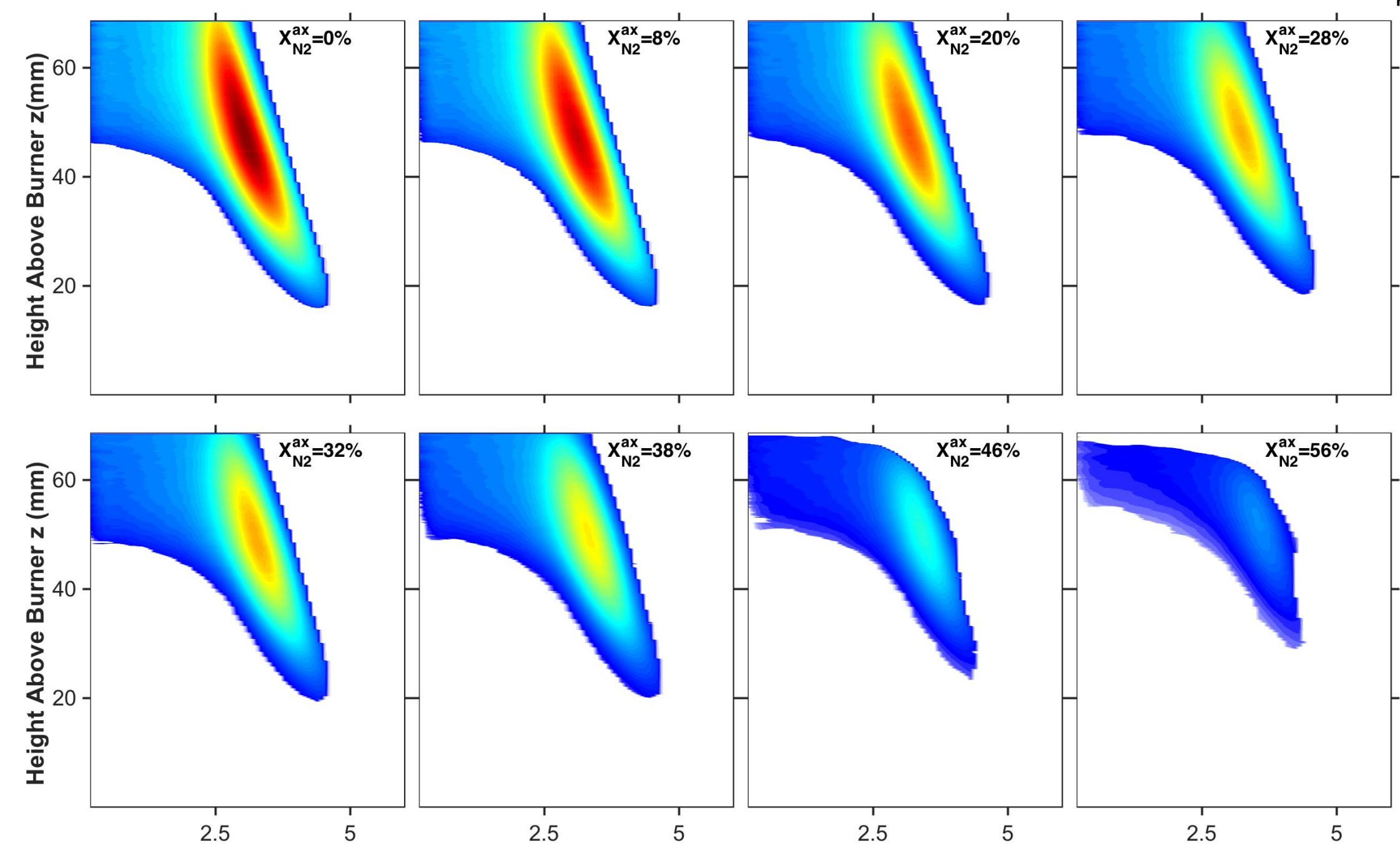

Radiative balance. $\mathrm{W} / \mathrm{m}$
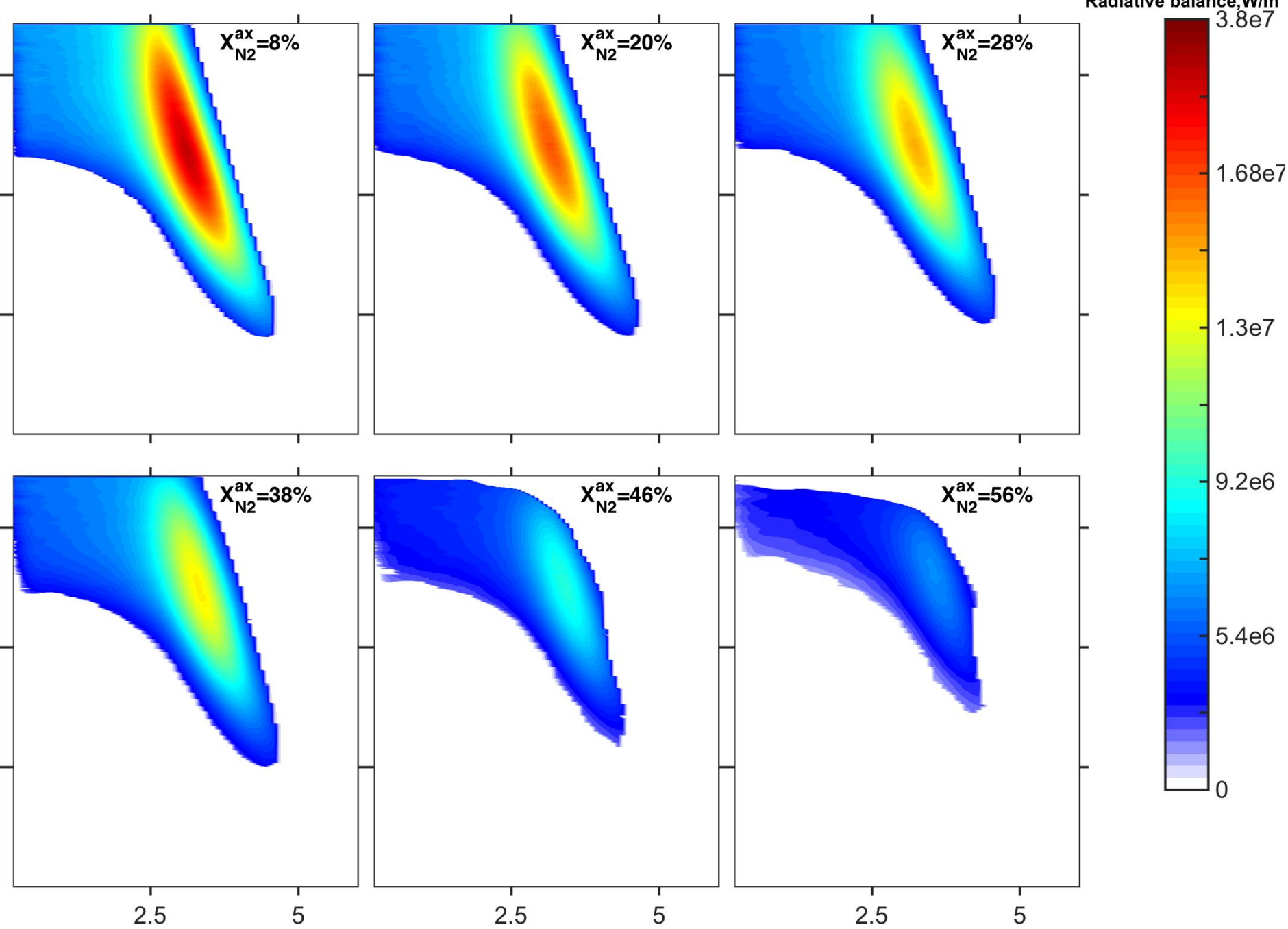

$-9.2 \mathrm{e} 6$ 
Declaration of Competing Interest

The authors declare that they have no known competing financial interests or personal relationships that could have appeared to influence the work reported in this paper. 
Qianlong WANG: Conceptualization, Data curation, Writing- Original draft preparation, Funding acquisition; Jean-Louis Consalvi: Resources, Software; Celine Morin: Writing - review \& editing; Guillaume LEGROS, Conceptualization; Fengshan LIU: Formal analysis, Investigation; Weiwei CAI: Writing - review; Haifeng LIU: Writing - review, Funding acquisition; 


\section{Supplementary materials}

The calculated oxygen/nitrogen diluted soot local radiative fields were supplied as the supplemental material. The following table detailed txt data names that correlated to the corresponding diluted fraction experimental conditions.

\begin{tabular}{|c|c|c|c|c|c|c|c|c|}
\hline Data name & santoro_a & santoro_b & santoro_c & santoro_d & santoro_e & santoro_f & santoro_g & \\
\hline $\begin{array}{l}\text { Experiment } \\
\text { Condition }\end{array}$ & $\mathrm{X}^{\mathrm{ax}}{ }_{\mathrm{o} 2}=0$ & $\mathrm{X}^{\mathrm{ax}}{ }_{\mathrm{o} 2}=8 \%$ & $\mathrm{X}^{\mathrm{ax}}{ }_{\mathrm{o} 2}=14 \%$ & $\mathrm{X}^{\mathrm{ax}}{ }_{02}=20 \%$ & $\mathrm{X}^{\mathrm{ax}}{ }_{02}=28 \%$ & $\mathrm{X}^{\mathrm{ax}}{ }_{02}=30 \%$ & $\mathrm{X}^{\mathrm{ax}}{ }_{\mathrm{o} 2}=32 \%$ & \\
\hline Data name & santoroN_a & santoroN_b & santoroN_c & santoroN_d & santoroN_e & santoroN_f & santoroN_g & santoroN_h \\
\hline $\begin{array}{l}\text { Experiment } \\
\text { Condition }\end{array}$ & $\mathrm{X}^{\mathrm{ax}}{ }_{\mathrm{n} 2}=0$ & $\mathrm{X}^{\mathrm{ax}}{ }_{\mathrm{n} 2}=8 \%$ & $\mathrm{X}^{\mathrm{ax}}{ }_{\mathrm{n} 2}=20 \%$ & $\mathrm{X}^{\mathrm{ax}}{ }_{\mathrm{n} 2}=28 \%$ & $\mathrm{X}^{\mathrm{ax}}{ }_{\mathrm{n} 2}=32 \%$ & $\mathrm{X}^{\mathrm{ax}}{ }_{\mathrm{n} 2}=38 \%$ & $\mathrm{X}^{\mathrm{ax}}{ }_{\mathrm{n} 2}=46 \%$ & $\mathrm{X}^{\mathrm{ax}}{ }_{\mathrm{n} 2}=56 \%$ \\
\hline
\end{tabular}

